\title{
Effect of thermal treatment on solid-solid interface of hematite thin film synthesized by spin-coating deposition solution
}

\author{
Daniel Angel Bellido-Aguilar a , Aryane Tofanello a , Flavio L. Souza a,*, \\ Leonardo Negri Furini ${ }^{\mathrm{b}}$, Carlos José Leopoldo Constantino ${ }^{\mathrm{b}}$ \\ a Centro de Ciências Naturais e Humanas (CCNH), Universidade Federal do ABC, Av. dos Estados N5001, Bangu, Santo André, São Paulo CEP 09210-580, Brazil \\ b Faculdade de Ciências e Tecnologia (FCT), UNESP Univ Estadual Paulista, Presidente Prudente, São Paulo, 19060-900, Brazil
}

\section{A R T I C L E I N F O}

\section{Article history:}

Received 1 August 2015

Received in revised form 4 February 2016

Accepted 4 March 2016

Available online 5 March 2016

\section{Keywords:}

Iron oxide

Nanostructure

Thin film

Doping

\begin{abstract}
A B S T R A C T
This work describes hematite films prepared by a spin-coating deposition solution (SCDS) method that is a sol-gel method derived technique. Hematite films were prepared at two heat treatment temperatures $\left(500{ }^{\circ} \mathrm{C}\right.$ and $800^{\circ} \mathrm{C}$ ) and the influence of thermal treatment on the photoelectrochemical performance was studied. In addition, since the SCDS method allows an optimal control of stoichiometry and impurity incorporation, hematite films modified with $\mathrm{Zn}^{2+}$ and $\mathrm{Sn}^{4+}$ were also prepared. The $800{ }^{\circ} \mathrm{C}$-treated hematite films had a higher wettability and roughness that enabled them to have a better photocatalytic response in comparison with that of $500{ }^{\circ} \mathrm{C}$-treated hematite films. Moreover, modified hematite films demonstrated to have a performance slightly better than that of undoped hematite film as shown in linear sweep voltammetry and chronoamperometry results. Although an improvement in the performance of hematite films was achieved by annealing at higher temperatures and incorporating $\mathrm{Zn}^{2+}$ or $\mathrm{Sn}^{4+}$, the general photocatalytic response of the films was poor. Two plausible hypotheses were discussed related to the (i) dopant segregation at grain boundary, and (ii) poor contact between the hematite and fluorine doped tin oxide layer (from the glass substrate), which was experimentally confirmed by a cross-sectional analysis conducted using scanning electron microscopy (SEM). In fact, additional experiments need to be done in order to improve the hematite deposition and make the SCDS a promise method for industrial application.
\end{abstract}

(C) 2016 Elsevier B.V. All rights reserved.

\section{Introduction}

Fossil fuels have been the most consumed energy by the world during the last 40 years. Indeed, fossil fuels provided approximately $87 \%$ of global energy consumption in 2013 [1,2]. Using this kind of energy will continue to provoke the emission of greenhouse gases (e.g. $\mathrm{CO}_{2}$ ) that pollute and damage our environment [3]. Therefore, optimizing the technology of clean and renewable energies is urgent in order to diminish the use of fossil fuels, and, thus, it will permit the preservation of our environment for the next generations.

Solar energy has attracted the researchers' interest because it is an unlimited source that can supply the current and future global energy demand [4]. Because solar energy is intermittent, one way to use solar energy is by converting it into a fuel such as hydrogen. Indeed, the solar hydrogen production is a promising technology for solar energy harvesting because hydrogen can be generated from the splitting of the molecule of water in photoelectrochemical cells. Thus, this strategy makes use of an unlimited and clean source like the sun and water to produce a high-energy fuel such as hydrogen $[5,6]$.

\footnotetext{
* Corresponding author.

E-mail addresses: flavio.souza@ufabc.edu.br, fleandro.ufabc@gmail.com (F.L. Souza).
}

Alpha iron oxide or hematite is an excellent candidate for photoanodes in photoelectrochemical cells. Hematite is an N-type semiconductor, and, because of the position of its conduction and valence bands, it is capable of performing only the water oxidation. Moreover, the most attracting characteristics of the hematite are its stability in neutral and basic solutions, abundance and band gap energy (2.0-2.2 eV) which permits it to absorb approximately $40 \%$ of the incident solar spectrum on earth. Nevertheless, the performance of hematite electrodes for water oxidation is restricted by their poor charge transport properties. Hematite has low conductivity and low charge-carrier mobility $\left(<1 \mathrm{~cm}^{2} \mathrm{~V}^{-1} \mathrm{~s}^{-1}\right)$. In addition, the photoexcited electron-hole pairs have short life time $\left(\sim 10^{-12} \mathrm{~s}\right)$, which makes the hole diffusion length to be also short $(2-4 \mathrm{~nm})[7,8]$. Because the holes participate in the water oxidation at the electrode-electrolyte interface, holes with short diffusion lengths can easily recombine, and, thus, affecting the efficiency of the surface chemical reaction [8].

The charge transport properties of hematite can be improved by doping. Researchers demonstrated to increase the conductivity of hematite by doping it with metal cations with $4^{+}$charge such as $\mathrm{Ti}$ [9], Sn [10], Si [11], which improved the photocatalytic properties. Doping with metal cations with $2^{+}$charges has also brought good photoelectrochemical results. For instance, Jiri Frydrych and co- 
workers presented a method for the deposition of nanocrystalline hematite photoelectrodes based on the spin-coating of a mixed solution containing $\mathrm{Sn}$ (II) and $\mathrm{Fe}$ (III) chlorides followed by thermal treatment. The highest photocurrents achieved was $0.45 \mathrm{~mA} \mathrm{~cm}^{2}$ at $1.43 \mathrm{~V}$ vs RHE for Sn-doped hematite photoelectrodes (with $\mathrm{Sn}$ :Fe ratio at 20:100) [12]. Kumari et al. prepared hematite films doped with $\mathrm{Zn}$ [13], and, the authors showed that, although Zn-modified film had a lower charge carrier density, $\mathrm{Zn}$ decreased the onset photocurrent potential, which resulted in a better photocurrent. Furthermore, the modification of hematite films with divalent metal cation can increase the carrier concentration (acting as donor), as demonstrated by Liu et al. [14] who prepared Ni-modified films, and the results confirmed that doping with nickel improved photocatalytic response of hematite.

Our group has been working with hematite films prepared by spincoating deposition solution (SCDS), and three important investigations were conducted until now. First, was studied the influence of film thickness on the hematite performance, in which it was demonstrated that photocurrent density increases with increasing the thickness of the film [15]. Most importantly, it was proved that the thinnest film had the poorest performance due to the stress induced between the hematite and the substrate, which caused the creation of intermediate levels trapping electrons close to the conduction band. Second, another limitation on the hematite films was related to the contact between the hematite and $\mathrm{F}-\mathrm{SnO}_{2}$ layer [16]. Cross-section STEM images of hematite film showed that the hematite layer adhered to few regions of the $\mathrm{F}-\mathrm{SnO}_{2}$ layer, which severely reduced the electron density collection. Third, the insertion of dopants on the photocatalytic response of hematite was also studied [17]. It was showed that Si dopants segregated at the grain boundaries, which caused the reduction in the grain size and favored the hole-electron recombination. In addition, the best photocurrent density of modified hematite film to its higher degree of preferential orientation to the (110) plane. In this context, we extended our investigations of the hematite film performance for the water oxidation reaction.

This work describes the preparation of undoped and doped hematite films by using SCDS method that is a sol-gel technique derived method (also named polymerized complex method in the literature). The films prepared by the SCDS were subjected to thermal treatments at 500 and $800{ }^{\circ} \mathrm{C}$, and the influence of these thermal treatments on the photocatalytic properties was studied. Furthermore, the influence of two dopants with different charges $\left(\mathrm{Sn}^{4+}\right.$ and $\left.\mathrm{Zn}^{2+}\right)$ on the hematite film performance was also investigated.

\section{Experimental details}

Undoped and doped-hematite films were prepared by using the spin-coating deposition solution (SCDS) as reported by Souza and coworkers [17]. The solutions were prepared in absolute ethanol (Absolute, 99.5\%, Synth) instead of water. For the preparation of the doped-hematite films, $0.5 \mathrm{~mol} \%$ of the dopant precursors $\left(\mathrm{Zn}\left(\mathrm{NO}_{3}\right)_{2}\right.$ and $\mathrm{SnCl}_{4}$ ) was used in relation to the iron cation $\left(\mathrm{FeCl}_{3} \cdot 6 \mathrm{H}_{2} \mathrm{O}\right)$.

Hematite thin films were produced on glasses coated with fluorinedoped tin oxide (FTO) by the spin coating technique. A set (three) of films were thermally treated at $500{ }^{\circ} \mathrm{C}$ for $2 \mathrm{~h}$, whereas the other three films were subjected at $800{ }^{\circ} \mathrm{C}$ for $30 \mathrm{~min}$, and the heating rate and cooling rate were $3{ }^{\circ} \mathrm{C} / \mathrm{min}$ and $1{ }^{\circ} \mathrm{C} / \mathrm{min}$, respectively. These temperatures of thermal treatment were chosen based in a systematic investigation about the influence of the temperature and time of treatments to obtain high-purity hematite phases, recently reported by our group [18].

The identification of the crystal structure of the films was carried out by X-ray diffraction (D8 Discover, Bruker-ASX) with a CuK $\alpha$ X-radiation source set at $0.5^{\circ}$ relative to the film surface. Raman spectra were obtained with a micro-Raman spectrograph (Renishaw, model in-Via) using a $514 \mathrm{~nm}$ laser and an 1800 lines/mm grating equipped with an optical microscope (Leica). All Raman spectra were carried out with 5 accumulations and $10 \mathrm{~s}$ of collecting time. Scanning electron microscopy (SEM, FEI Inspect F50) was carried out for studying the morphological features of the films.

The film roughness was assessed by atomic force microscope (AFM, SPM 5500, Agilent) in non-contact mode. A commercial drop shape analysis system (Attension Optical Tensiometer, Theta Lite, KSV/ CAM101) was used to measure the static contact angles formed between a sessile water drop and films surface at room temperature. Contact angles were measured during the first $60 \mathrm{~s}$, and the final contact angle was recorded (reported as the average of the left and right angles).

By using a potentiostat/galvanostat ( $\mu$ Autolab III) coupled with FRA (impedance spectroscopy module), linear sweep voltammetry, chronoamperometry and electrochemical impedance spectroscopy (EIS) were performed in a three-electrode electrochemical cell containing $\mathrm{NaOH}$ solution $\left(1 \mathrm{M}, \mathrm{pH}=13.6\right.$ at $\left.25^{\circ} \mathrm{C}\right)$. A saturated $\mathrm{Ag} / \mathrm{AgCl}$ electrode, a platinum electrode and the prepared films were used as the reference electrode, counter electrode and the working electrode, respectively. The prepared films were illuminated through the glass side for the measurements of the photocurrents by using an AM 1.5G simulated sunlight $\left(100 \mathrm{~mW} / \mathrm{cm}^{2}\right)$. For the EIS measurements, it was applied $10 \mathrm{mV}$ as the perturbation amplitude.

\section{Results}

The X-ray diffraction patterns of the undoped hematite films are displayed in Fig. 1. The diffraction peaks were indexed comparing with the XRD pattern of the standard hematite powder (JCPDS card No. 33-0664). Undoped $500{ }^{\circ} \mathrm{C}$ and $800{ }^{\circ} \mathrm{C}$-treated films had a XRD pattern typical of the hematite phase (Fig. 1a). In addition, it was identified the diffraction peaks related to the fluorine-doped tin oxide (FTO) layer presented in the commercial glass substrate by using the JCPDS card No. 41-1445 ( $\mathrm{SnO}_{2}$ cassiterite phase). Additional diffraction peaks due to the formation of other phases were not found. In Fig. 1b and $c$ are shown the XRD patterns of the films modified with $\mathrm{Sn}^{4+}$ and $\mathrm{Zn}^{2+}$ which also corresponded to that of hematite phase. Even though it is possible the formation of $\mathrm{SnO}_{2}$ due to segregation of the $\mathrm{Sn}^{4+}$ dopant, we have ascribed the diffraction peaks of the $\mathrm{SnO}_{2}$ cassiterite to the FTO layer because all the films were prepared onto FTO substrates. Moreover, the presence of other phase was not identified.

On the other hand, it is worth to mention that the diffraction peaks of the $800{ }^{\circ} \mathrm{C}$-treated films were sharper and more intense than those of $500{ }^{\circ} \mathrm{C}$-treated films. This implies that the films prepared at higher temperatures could lead to higher grain size than those $500^{\circ} \mathrm{C}$-hematite treated films.

In order to investigate the incorporation of dopants into the hematite structure, the unit cell parameters and volumes were calculated by using the X-ray diffraction data and the free software named CellCal [19] (Table 1). The calculated parameters were close to those of the standard hematite powder, which confirmed that the films crystallized in the hematite phase. Moreover, the lattice parameters and unit cell volumes of the doped-hematite films were similar to those of undoped hematite films. Usually, a change in the volume or unit cell dimensions is expected when $\mathrm{Zn}^{2+}$ and $\mathrm{Sn}^{4+}$ ions substitute $\mathrm{Fe}^{3+}$ ion (hexacoordinated $\mathrm{Fe}^{3+}$, high spin) because of the different ionic radii: $0.74,0.69$ and $0.645 \AA$, respectively [20]. Therefore, these results suggested that the dopants were not incorporated into the hematite structure by replacing $\mathrm{Fe}^{3+}$ ion. On the other hand, $\mathrm{Zn}^{2+}$ and $\mathrm{Sn}^{4+}$ can be incorporated into some interstitial sites of the hematite structure. In the hematite structure, oxygen ions form a hexagonal close packing in which $\mathrm{Fe}^{3+}$ ions occupy two-thirds of the octahedral interstices. Therefore, octahedral and tetrahedral interstices are available and can be occupied by dopants. Indeed, based on structural refinement results, it was proposed that $\mathrm{Sn}^{4+}$ could occupy the empty octahedral interstices of hematite [21,22]. Moreover, since $\mathrm{Zn}^{2+}$ has a comparable size as that of the $\mathrm{Sn}^{4+}$, 

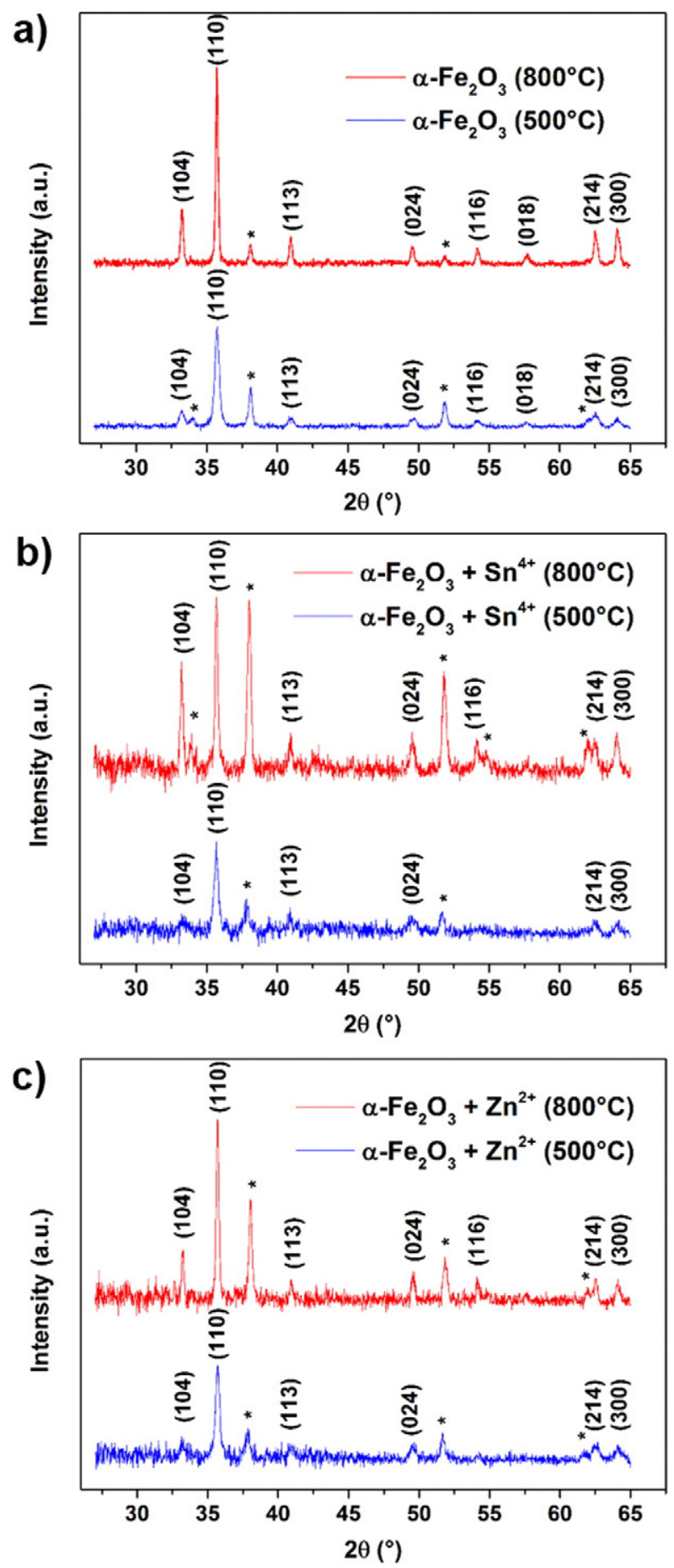

Fig. 1. XRD patterns of hematite films prepared by the SCDS method at two different temperatures: (a) undoped films, (b) Sn-doped hematite films and (c) Zn-doped hematite films. Asterisks indicate the diffraction peaks of the $\mathrm{F}-\mathrm{SnO}_{2}$ layer.

$\mathrm{Zn}^{2+}$ could occupy octahedral interstices. Nevertheless, it is also possible that the cell parameters and cell volumes did not varied much because of the low concentration of the dopants. In other words, the X-ray diffraction technique was not sensitive enough to detect a crystal distortion caused by low amount of dopants. For instance, Uchiyama et al. [23] prepared tin-doped hematite films by using higher concentration of tin ( $10 \mathrm{~mol} \%$ and $25 \mathrm{~mol} \%$ ), and doping was proved because the XRD peaks of the doped hematite films shifted slightly. For this reason, a more sensitive technique should be used in order to confirm whether or not hematite films were doped with $\mathrm{Zn}^{2+}$ e $\mathrm{Sn}^{4+}$.

In addition to the cell parameters and volumes, the degree of preferential orientation of the hematite crystallites was assessed by using the Lotgering's equation [24]:

$F=\frac{\left(P-P_{0}\right)}{\left(1-P_{0}\right)}$

where $P=\sum I(h 00) / \sum I(h k l), I$ is the diffraction peak intensity and $P_{0}$ is the same as $P$ for the non-oriented sample (standard hematite powder). The results showed that the (110) plane had the highest $F$ value (Table 2), which means that the hematite crystallites are preferentially aligned parallel to the FTO conductive layer of the substrate. Furthermore, the (110) plane was not affected by insertion of dopant or temperature of thermal treatments.

Because most of hematite crystallites had the (110) plane as preferential orientation, the basal plane (001) became oriented perpendicular to FTO conductive layer of the substrate. The (001) plane of the hematite crystallites may have a conductivity up to 4 order of magnitudes higher than orthogonal planes to it [25]. Therefore, having the (001) plane oriented perpendicular to the FTO layer could enhance the charge transfer that, in turn, improves the efficiency of the water oxidation at the solid-liquid interface. Thus, the SCDS method permitted to prepare hematite films having the (001) plane perpendicular to the FTO, and, therefore, favoring the catalytic response under illumination.

Another important information that was obtained from XRD data was the hematite crystallite sizes. The crystallite sizes of hematite films were estimated by using the Scherrer's equation [26]:

$L=\frac{K \lambda}{\beta \cos \theta}$

where $\lambda$ is the X-ray wavelength (nm), $K$ is a constant usually taken as 0.9 [27]; $\theta$ is the diffraction angle (radians) and $\beta$ is the diffraction peak width at half maximum height. By using the diffraction peaks data of (110), (104) and (300) planes, the Scherrer's equation was solved and the estimated crystallite sizes are shown in Table 1 . The $500{ }^{\circ} \mathrm{C}$-treated hematite films had a smaller crystallite size than that of $800{ }^{\circ} \mathrm{C}$-treated films estimated at (110) plane. Additionally, the results suggested that the incorporation of $\mathrm{Zn}^{2+}$ and $\mathrm{Sn}^{4+}$ during the synthesis process seems does not affect the crystallite sizes of the $500{ }^{\circ} \mathrm{C}$-treated hematite films estimated at (110) and (104) planes (see Table 1). In contrast, modified hematite films prepared at $800{ }^{\circ} \mathrm{C}$ had considerably smaller crystallite sizes estimated at (110) plane and remained practically constant at (104) plane in comparison with those of undoped film. In addition, the Scherrer equation was used to determine the crystallite size of all hematite film in (300) plane exhibiting a reduction of crystallite size with incorporation of $\mathrm{Zn}^{2+}$ and $\mathrm{Sn}^{4+}$ in both cases. In summary, the introduction of $\mathrm{Zn}^{2+}$ and $\mathrm{Sn}^{4+}$ affect the crystallite size avoiding the grain growth mechanism of hematite films. These results suggest that the dopants are segregating in the hematite grain surface at (104) planes for 500 and 800-treated hematite films causing a reduction of crystallite size. In fact, this effect was reported in a previous investigation (using XPS technique) with introduction of Si as dopant in hematite film produced by the same method [16]. The Si-doping hematite films were found preferentially on the surface of hematite grains instead bulk of hematite crystal $[17,28]$. This could also explain the worm-like shape observed in SEM images (discussed later) for all hematite films prepared by this method and the hematite crystal preferential orientation in (110) plane (see values of $F$ on Table 1 ).

Raman spectroscopy was carried out since it allows examining the vibrational modes of chemical bonds that may be influenced by the incorporation of dopants.

In Fig. 2 are exhibited the Raman spectra of all hematite films prepared by SCDS method. Hematite belongs to the point group $\mathrm{D}_{3 \mathrm{~d}}$, 
Table 1

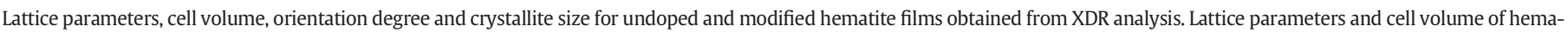
tite standard powder were included as reference.

\begin{tabular}{|c|c|c|c|c|c|c|c|}
\hline Sample & $\mathrm{a}(\AA)$ & $c(\AA)$ & $V\left(\AA^{3}\right)$ & $\begin{array}{l}\text { Highest } F((110) \\
\text { plane) }\end{array}$ & $\begin{array}{l}\text { Crystallite size (104) } \\
(\mathrm{nm})\end{array}$ & $\begin{array}{l}\text { Crystallite size (110) } \\
(\mathrm{nm})\end{array}$ & $\begin{array}{l}\text { Crystallite size (300) } \\
(\mathrm{nm})\end{array}$ \\
\hline JCPDS-33-0664 & 5.036 & 13.7 & 301.9 & & & & \\
\hline$\alpha-\mathrm{Fe}_{2} \mathrm{O}_{3}\left(500{ }^{\circ} \mathrm{C}\right)$ & $5.024( \pm 0.004)$ & $13.767( \pm 0.019)$ & $300.985( \pm 0.657)$ & 0.45 & 17.3 & 22.1 & 16.0 \\
\hline$\alpha-\mathrm{Fe}_{2} \mathrm{O}_{3}+\mathrm{Sn}^{4+}\left(500{ }^{\circ} \mathrm{C}\right)$ & $5.022( \pm 0.005)$ & $13.797( \pm 0.060)$ & $301.377( \pm 1.440)$ & 0.35 & 18.2 & 23.1 & 12.9 \\
\hline$\alpha-\mathrm{Fe}_{2} \mathrm{O}_{3}+\mathrm{Zn}^{2+}\left(500{ }^{\circ} \mathrm{C}\right)$ & $5.022( \pm 0.005)$ & $13.729( \pm 0.056)$ & $299.799( \pm 1.334)$ & 0.36 & 19.7 & 22.8 & 12.8 \\
\hline$\alpha-\mathrm{Fe}_{2} \mathrm{O}_{3}\left(800{ }^{\circ} \mathrm{C}\right)$ & $5.030( \pm 0.001)$ & $13.723( \pm 0.005)$ & $300.715( \pm 0.171)$ & 0.37 & 37.3 & 42.5 & 25.2 \\
\hline$\alpha-\mathrm{Fe}_{2} \mathrm{O}_{3}+\mathrm{Sn}^{4+}\left(800^{\circ} \mathrm{C}\right)$ & $5.032( \pm 0.001)$ & $13.739( \pm 0.010)$ & $301.238( \pm 0.279)$ & 0.20 & 37.1 & 35.1 & 23.2 \\
\hline$\alpha-\mathrm{Fe}_{2} \mathrm{O}_{3}+\mathrm{Zn}^{2+}\left(800^{\circ} \mathrm{C}\right)$ & $5.029( \pm 0.001)$ & $13.722( \pm 0.007)$ & $300.509( \pm 0.197)$ & 0.37 & 39.5 & 36.8 & 17.9 \\
\hline
\end{tabular}

and, theoretically, a pure and non-defective hematite monocrystal should exhibit five $\mathrm{E}_{\mathrm{g}}$ modes and two $\mathrm{A}_{1 \mathrm{~g}}$ modes that are Raman active [29]. Those seven characteristic vibrational modes were also found for the polycrystalline undoped hematite films prepared at $500{ }^{\circ} \mathrm{C}$ and $800{ }^{\circ} \mathrm{C}$ (Fig. 2a), and they were labeled according to literature [29]. As noted, the Raman bands of the $800{ }^{\circ} \mathrm{C}$-treated undoped hematite film were sharper and more intense (higher signal/noise ratio) than those of the $500{ }^{\circ} \mathrm{C}$-treated undoped film (Fig. 2a). Since less intense and broad Raman bands are related to the crystallite or grain size [30,31], the Raman spectra illustrated in Fig. 2a suggested that hematite crystallites grow with increasing the temperatures of thermal treatment. In fact here, the change in the intensity of the Raman bands can be attributed to the difference of crystallite size. According to the crystallite sizes estimated from Scherrer's equation, the $500{ }^{\circ} \mathrm{C}$-treated films exhibited smaller crystallite sizes than those of $800{ }^{\circ} \mathrm{C}$-treated hematite films. Therefore, the $800{ }^{\circ} \mathrm{C}$-treated undoped hematite film had a higher intensity of the Raman bands because it was composed of larger grains. The grain or crystallite size affecting the Raman intensity has been reported in the literature [30,31].

Besides the characteristic vibrational modes of hematite, one additional Raman band at about $660 \mathrm{~cm}^{-1}$ was observed for the polycrystalline undoped films (Fig. 2a). According to reports, this band has been attributed to the presence of magnetite residues or to the crystal disorder in hematite lattice [32-34]. Since the XRD results did not show the presence of others iron oxide phases, we believe that Raman band at $\sim 660 \mathrm{~cm}^{-1}$ must be related to the crystal disorder of hematite. It seems that this band at $\sim 660 \mathrm{~cm}^{-1}$ is more pronounced for the $800{ }^{\circ} \mathrm{C}$-treated undoped hematite film (Fig. 2a). However, one should pay attention to the fact the whole Raman spectrum (the seven typical vibrational modes of hematite) of the $500{ }^{\circ} \mathrm{C}$-treated undoped hematite film (Fig. 2a) is indeed less defined (decrease in signal/noise ratio) than the spectrum for the $800{ }^{\circ} \mathrm{C}$-treated undoped hematite film (Fig. 2a). The latter suggests the $800{ }^{\circ} \mathrm{C}$-treated hematite film has larger crystallite size than $500{ }^{\circ} \mathrm{C}$-treated hematite film, consistent with values estimated by X-ray diffraction data. Besides, the loss of Raman band definition (decrease in signal/noise ratio) is also observed in Fig. 2b and $\mathrm{c}$ when the Raman spectra of the undoped hematite films $\left(800{ }^{\circ} \mathrm{C}\right.$ and $500{ }^{\circ} \mathrm{C}$ ) are compared with the Raman spectra of the treated modified films $\left(800{ }^{\circ} \mathrm{C}\right.$ and $500{ }^{\circ} \mathrm{C}$ ), which clearly must be due to the presence of the dopant ions in these samples. The latter may be related with substitutional solid solution, otherwise, a

\section{Table 2}

Photocurrent density, $J$, at $1.23 \mathrm{~V}_{\mathrm{RHE}}$ obtained from linear sweep voltammetry results for hematite electrodes.

\begin{tabular}{ll}
\hline Hematite films & $\begin{array}{l}J\left(\mu \mathrm{A} / \mathrm{cm}^{2}\right) \\
(1.23 \mathrm{~V} \text { vs RHE })\end{array}$ \\
\hline$\alpha-\mathrm{Fe}_{2} \mathrm{O}_{3}\left(500^{\circ} \mathrm{C}\right)$ & 17.7 \\
$\alpha-\mathrm{Fe}_{2} \mathrm{O}_{3}+\mathrm{Sn}^{4+}\left(500^{\circ} \mathrm{C}\right)$ & 34.8 \\
$\alpha-\mathrm{Fe}_{2} \mathrm{O}_{3}+\mathrm{Zn}^{2+}\left(500^{\circ} \mathrm{C}\right)$ & 17.0 \\
$\alpha-\mathrm{Fe}_{2} \mathrm{O}_{3}\left(800^{\circ} \mathrm{C}\right)$ & 15.8 \\
$\alpha-\mathrm{Fe}_{2} \mathrm{O}_{3}+\mathrm{Sn}^{4+}\left(800^{\circ} \mathrm{C}\right)$ & 24.6 \\
$\alpha-\mathrm{Fe}_{2} \mathrm{O}_{3}+\mathrm{Zn}^{2+}\left(800^{\circ} \mathrm{C}\right)$ & 27.2 \\
\hline
\end{tabular}

simple segregation of the ions (grain boundary) would not lead to the significant spectral changes as we observed.

The morphological features of the films were studied from images obtained by scanning electron microscopy (Fig. 3). The grain shape of all the films was like worms and very similar to that of hematite films prepared by Souza et al. [17]. Clearly, the grains of $800^{\circ} \mathrm{C}$-treated hematite films (Fig. b, d, f) were higher than those of $500^{\circ} \mathrm{C}$-treated hematite film (a, c, e). This was also proved by the measurements of the grain lengths. In relation to the films $500{ }^{\circ} \mathrm{C}$-treated hematite film, the mean lengths of the grains for the undoped film, Sn-modified hematite film, and Zn-modified hematite film were 182, 193, and $189 \mathrm{~nm}$, respectively. Concerning $800^{\circ} \mathrm{C}$-treated hematite film, the mean lengths of the grains were 300,265 , and $255 \mathrm{~nm}$ for the undoped film, Sn-modified hematite film and Zn-modified hematite, respectively. Therefore, the length of the hematite grains increased with increasing the thermal treatment temperature. In addition, the grains of the $800{ }^{\circ} \mathrm{C}$-treated hematite films were not only bigger because of their large lengths but also because of the fact that they were thicker.

As shown in Table 1, the crystallite sizes estimated by Scherrer's equation were quite different from the grain lengths measured from SEM images. This indicated that the grains of the hematite films are composed of various crystallites. In addition, it is worth to mention that Scherrer's equation correctly predicted that $500{ }^{\circ} \mathrm{C}$-treated hematite film would have smaller grains in comparison with those of $800^{\circ} \mathrm{C}$-treated hematite film. Furthermore, SEM images of $800^{\circ} \mathrm{C}$-treated films showed that the grains of the modified films were smaller than those of the undoped film, which was also suggested by the estimated crystallite sizes from Scherrer's equation.

In addition for having bigger grains, $800{ }^{\circ} \mathrm{C}$-treated hematite film were porous and seemed to be rough, while $500{ }^{\circ} \mathrm{C}$-treated hematite film had a compact and smooth surface. An accurate analysis of the surface roughness of hematite films was performed by atomic force microscopy and is discussed later. Moreover, photoelectrodes with high porosity are always preferred because more surface area is available for the water oxidation reaction. Therefore, it is expected that $800{ }^{\circ} \mathrm{C}$-treated hematite film exhibit a better photocatalytic response than that of $500{ }^{\circ} \mathrm{C}$-treated hematite film.

As mentioned, the grains of the $800{ }^{\circ} \mathrm{C}$-treated modified hematite film were smaller than those of the corresponding undoped film (Fig. 3 b, d, f). This indicated that the grain growths of the modified films were slowed by some agents. Therefore, it may be possible that to a certain degree the dopants $\mathrm{Sn}^{4+}$ and $\mathrm{Zn}^{2+}$ segregated at the grain boundaries, making the hematite grains grow slowly. Using the SCDS method, Souza et al. [17] prepared hematite films modified with silicon and also had a similar result to ours. According to the SEM images, Si-modified hematite films were composed of smaller grains in comparison with those of the undoped film. Indeed, the authors concluded that silicon segregated at the grain boundaries of hematite based on XPS results. Therefore, $\mathrm{Sn}^{4+}$ and $\mathrm{Zn}^{2+}$ may have segregated at the grain boundaries of the $800{ }^{\circ} \mathrm{C}$-treated hematite films. This hypothesis is also supported by the Raman results (Fig. 2c), in which the addition of dopants decreased the intensity of all the Raman bands. That effect is possible when dopants, being segregated at the grain boundaries, 

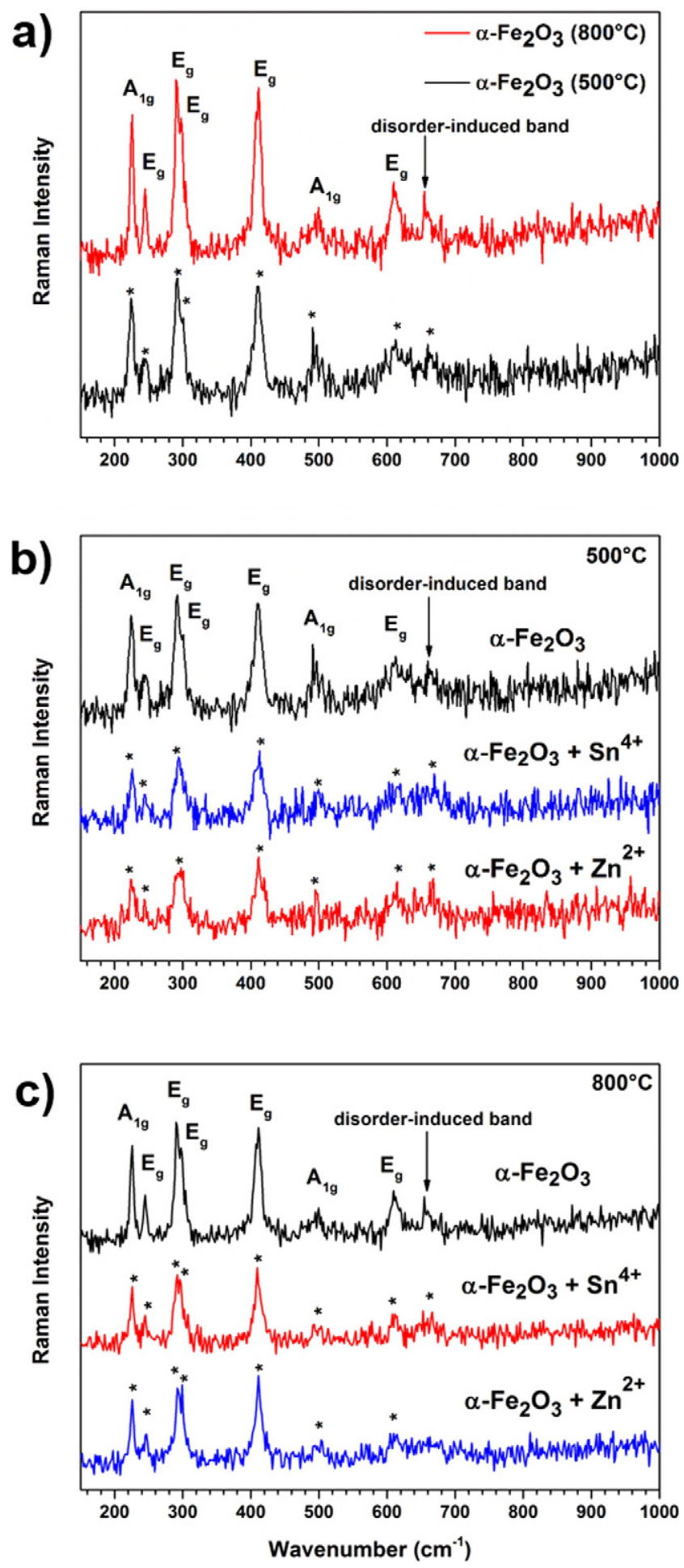

Fig. 2. Raman spectra: a) pure hematite films, b) films prepared at $500{ }^{\circ} \mathrm{C}$, and c) films prepared at $800{ }^{\circ} \mathrm{C}$. Well-defined bands are indicated with asterisks.

scatter the laser before it interacts with the hematite matrix, and, thus, low intense Raman band of hematite are recorded. Furthermore, the reduction in the Raman band intensity is also caused due to the smaller grains that formed into the modified hematite film in comparison with the grains of undoped film.

On the other hand, the thicknesses of the undoped films prepared at $500{ }^{\circ} \mathrm{C}$ and $800^{\circ} \mathrm{C}$ were measured (Fig. $3 \mathrm{~g}, \mathrm{~h}$ ). The $800{ }^{\circ} \mathrm{C}$-treated hematite film was thicker (an average of $285 \mathrm{~nm}$ ) than the $500{ }^{\circ} \mathrm{C}$-treated hematite film (an average of $162 \mathrm{~nm}$ ). These results were understandable and well related to the grain sizes. The $800{ }^{\circ} \mathrm{C}$-treated film was thicker because it was composed of higher grains that made the film to be more voluminous and porous. In contrast, the small grains well packed of the $500{ }^{\circ} \mathrm{C}$-treated film made it be thinner. Having an adequate thickness is important for a photoelectrode in order to absorb most of sunlight irradiated. For example, a hematite film of $400 \mathrm{~nm}$ thickness can absorb approximately $95 \%$ of the sunlight intensity of a $550 \mathrm{~nm}$ wavelength [35]. However, the semiconductor not only has to absorb most of the light intensity but also has to have a good charge transport in order to avoid the charge recombination and improve the water oxidation efficiency.

The electrochemical performances of the synthesized films were evaluated both in the dark and under illumination by means of linear sweep voltammetry (Fig. 4). In addition, the potential of the J-V curves was reported against the reversible hydrogen electrode (RHE) by using the following equation:

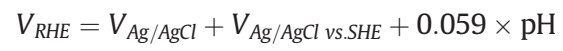

where $V_{A g / A g C l}$ vs.SHE is the potential of the $\mathrm{Ag} / \mathrm{AgCl}$ reference potential (in saturated $\mathrm{KCl}$ ) with respect to standard hydrogen potential (SHE).

The results showed that the oxygen evolution reaction (OER) took place at hematite film surface both in the dark and under illumination. Moreover, the thermal treatment temperature and doping influenced on the onset potential for the OER. In darkness, the OER started at approximately $1.5 \mathrm{~V}_{\mathrm{RHE}}$ in $500{ }^{\circ} \mathrm{C}$-treated hematite films (Fig. 4 a,c,e) while oxygen evolution started at higher potentials for $800{ }^{\circ} \mathrm{C}$-treated hematite film (Fig. 4 b,d,f). The influence of doping on the onset potential for OER is evident in the results recorded under illumination. The Snmodified $500{ }^{\circ} \mathrm{C}$ and $800{ }^{\circ} \mathrm{C}$-treated hematite film had a photocurrent onset potential of $\sim 0.65 \mathrm{~V}_{\mathrm{RHE}}$ and $\sim 0.64 \mathrm{~V}_{\mathrm{RHE}}$, respectively, while the other films had a photocurrent onset potential of $\sim 0.6 \mathrm{~V}_{\mathrm{RHE}}$.

The doping and temperature of thermal treatment influenced the onset potential for the OER and the photocurrent density. The photocurrent density of all the hematite films at $1.23 \mathrm{~V}_{\mathrm{RHE}}$ is summarized in Table 2. Regarding the effect of doping, $800{ }^{\circ} \mathrm{C}$-treated hematite film and modified with $\mathrm{Sn}^{4+}$ and $\mathrm{Zn}^{2+}$ exhibited a higher photocurrent than that of the undoped hematite film. In relation to the $500^{\circ} \mathrm{C}$-treated hematite film, only the Sn-modified hematite film had a higher photocurrent in comparison with that of the undoped film, while the incorporation of the $\mathrm{Zn}^{2+}$ into the hematite film made the film have a lower photocurrent. The effect of temperature was also evaluated. The results indicated that, with exception of $\mathrm{Zn}-\mathrm{Fe}_{2} \mathrm{O}_{3}$, the heat treatment at higher temperatures did not improve the catalytic response under illumination of hematite films. These results were not expected because dopants [23, $36]$ and thermal treatments at higher temperatures [37,38] generally enhance the performance of the hematite films.

In order to understand the linear sweep voltammetry results and evaluate the stability of the films, the chronoamperometry of the hematite films was recorded (Fig. 5). All the films had a spike of photocurrent during the first minutes, which meant that the films were unstable at the beginning of the measurements but then they held a photocurrent practically constant. The stability of films was evaluated by calculating the percent variation of the initial and final photocurrent density (Fig. 5). Furthermore, the photocurrent densities in function of time were also studied by considering the effect of temperature and doping on the photocatalytic properties of hematite films. Different from the linear sweep voltammetry results, chronoamperometry results proved that thermal treatment at higher temperatures enhanced the stability and photocurrent density. Moreover, in relation to effect of dopants, chronoamperometry results also showed that doping improved the performance of films with the exception of the $\mathrm{Zn}$-modified $500{ }^{\circ} \mathrm{C}$-treated hematite film. These last results were similar to the linear sweep voltammetry (Table 2) and confirmed that doping with $\mathrm{Zn}^{2+}$ did not enhance the photocatalytic response of the $500{ }^{\circ} \mathrm{C}$-treated hematite film. 

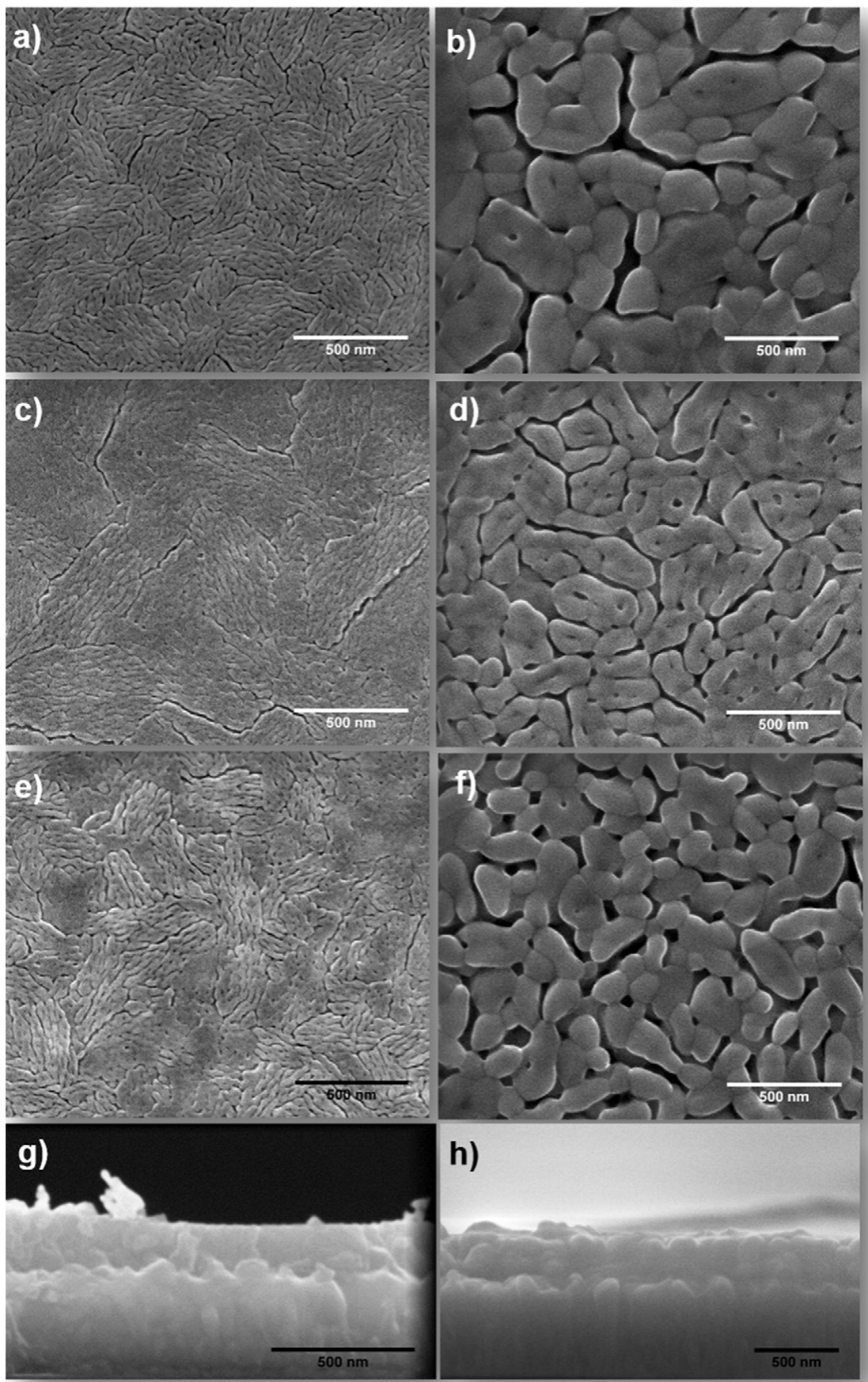

h)

Fig. 3. SEM images of hematite films: (a) $\alpha-\mathrm{Fe}_{2} \mathrm{O}_{3}\left(500{ }^{\circ} \mathrm{C}\right)$, (b) $\alpha-\mathrm{Fe}_{2} \mathrm{O}_{3}\left(800{ }^{\circ} \mathrm{C}\right)$, (c) $\alpha-\mathrm{Fe}_{2} \mathrm{O}_{3}+\mathrm{Sn}^{4+}\left(500{ }^{\circ} \mathrm{C}\right),(\mathrm{d}) \alpha-\mathrm{Fe}_{2} \mathrm{O}_{3}+\mathrm{Sn}^{4+}\left(800{ }^{\circ} \mathrm{C}\right)$, (e) $\alpha$ - $\mathrm{Fe}_{2} \mathrm{O}_{3}+\mathrm{Zn}^{2+}\left(500{ }^{\circ} \mathrm{C}\right)$ and f) $\alpha-\mathrm{Fe}_{2} \mathrm{O}_{3}+\mathrm{Zn}^{2+}\left(800^{\circ} \mathrm{C}\right)$. Cross-section images of the undoped films prepared at $(\mathrm{g}) 500^{\circ} \mathrm{C}$ and $(\mathrm{h}) 800{ }^{\circ} \mathrm{C}$.

On the other hand, electrochemical impedance spectroscopy was carried out in dark ness since it permits to obtain the flat band potential $\left(\mathrm{V}_{\mathrm{FB}}\right)$ and the density of charge carriers $\left(\mathrm{N}_{\mathrm{D}}\right)$ of semiconductor electrodes through the Mott-Schottky equation. The Mott-Schottky equation for an n-type semiconductor is [39]:

$\frac{1}{C^{2}}=\left(\frac{2}{q \varepsilon \varepsilon_{0} N_{D}}\right)\left(V-V_{F B}-\frac{k T}{q}\right)$

where $C$ is the capacitance of the depletion region, $N_{D}$ is charge carrier density, $V_{F B}$ is the flat band potential, $V$ is the applied potential, $\varepsilon_{0}$ is the electric permittivity of free space, $\varepsilon$ is the semiconductor dielectric constant $\left(\varepsilon_{\text {Hematite }}=80\right)$ [40], $q$ is the electron charge, $k$ is the Boltzmann constant and $T$ is the temperature. The $\mathrm{N}_{\mathrm{D}}$ and $\mathrm{V}_{\mathrm{FB}}$ values are obtained from the slope and $y$-axis intersection of the $1 / C^{2}$ versus $V$ plot, respectively.

The Mott-Schottky curves of the hematite films at $1 \mathrm{kHz}$ are shown in Fig. 6 . Theoretically, the $1 / C^{2}$ versus $V$ plot should be linear, but all the curves in Fig. 6 seemed to be concave downward with the exception of the curve of the $\mathrm{Sn}^{4+}$-modified $500{ }^{\circ} \mathrm{C}$-treated hematite films that had two linear regions. A possible explanation of these two types of abnormal Mott-Schottky graphs is found in the research of Leduc et al. [41] and 
a)
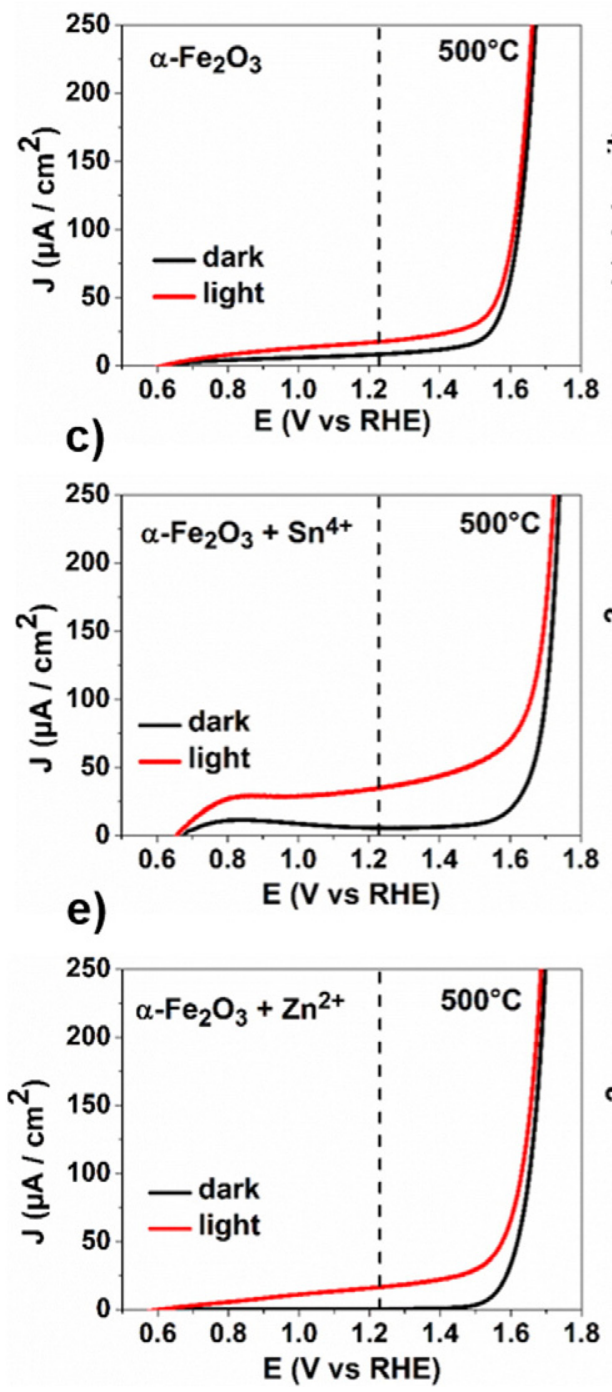

b)
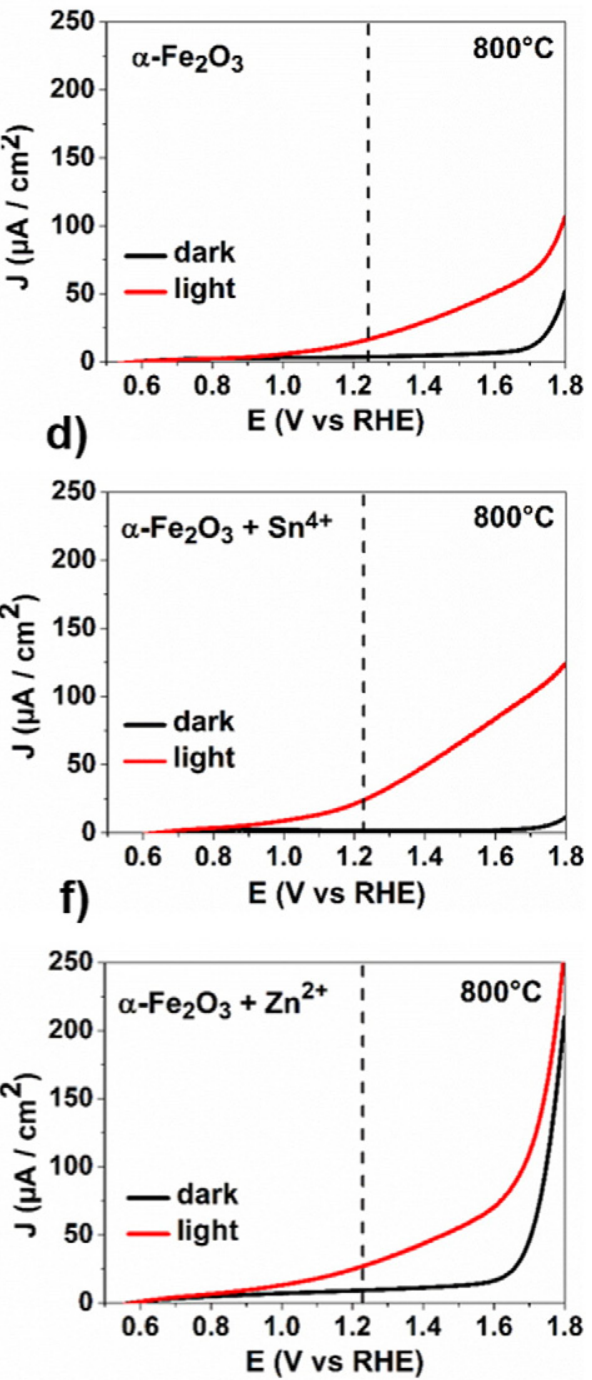

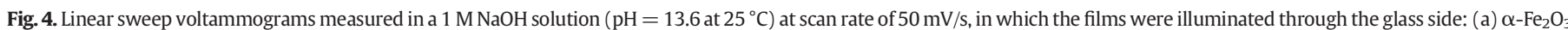
$\left(500{ }^{\circ} \mathrm{C}\right),(\mathrm{b}) \alpha-\mathrm{Fe}_{2} \mathrm{O}_{3}\left(800{ }^{\circ} \mathrm{C}\right),(\mathrm{c}) \alpha-\mathrm{Fe}_{2} \mathrm{O}_{3}+\mathrm{Sn}^{4+}\left(500{ }^{\circ} \mathrm{C}\right),(\mathrm{d}) \alpha-\mathrm{Fe}_{2} \mathrm{O}_{3}+\mathrm{Sn}^{4+}\left(800{ }^{\circ} \mathrm{C}\right),(\mathrm{e}) \alpha-\mathrm{Fe}_{2} \mathrm{O}_{3}+\mathrm{Zn}^{2+}\left(500{ }^{\circ} \mathrm{C}\right), \mathrm{and}(\mathrm{f}) \alpha-\mathrm{Fe}_{2} \mathrm{O} 3+\mathrm{Zn}^{2+}\left(800{ }^{\circ} \mathrm{C}\right)$

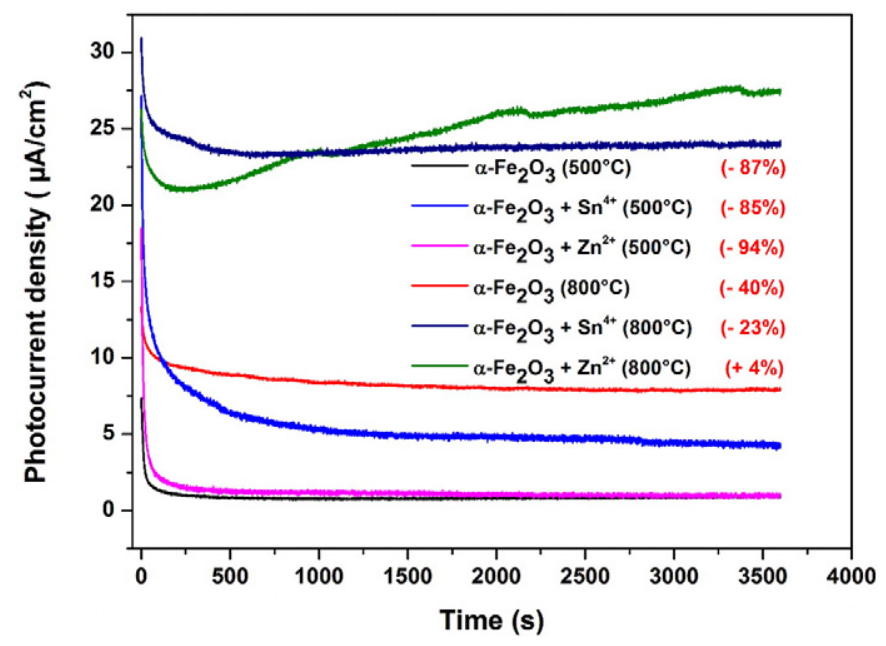

Fig. 5. Chronoamperograms of undoped and modified hematite films at $1.23 \mathrm{~V}_{\mathrm{RHE}}$ recorded under illumination. The percent variation of the photocurrent is given in red brackets.
Horowitz [42] who worked with hematite films. According to the work of Leduc et al., the plot being concave downward could be originated from the existence of deep donor level. In addition, Horowitz concluded that a Mott-Schottky plot having a break (which creates two linear regions) is modeled well for a semiconductor having both a deep donor level and a localized surface state. Even though a sole well-defined linear region was not found in the Mott-Schottky plots, estimations of the $N_{D}$ and $V_{F B}$ values were obtained from the linear region indicated with a red line in Fig. 6, and they are displayed in Table 3.

The estimated $\mathrm{N}_{\mathrm{D}}$ values were reasonable and similar to those reported in literature $[38,43-45]$. In relation to the $500{ }^{\circ} \mathrm{C}$-treated hematite film, results indicated that $\mathrm{Sn}^{4+}$ is acting as an acceptor since it caused a reduction in the $\mathrm{N}_{\mathrm{D}}$, while $\mathrm{Zn}^{2+}$ acted as donor increasing the $N_{D}$ in relation to the undoped hematite film. In addition, the results suggested that the $\mathrm{Sn}^{4+}$ was incorporated more efficiently into the hematite structure than $\mathrm{Zn}^{2+}$ was because $\mathrm{Sn}^{4+}$ provoked a greater change in the $\mathrm{N}_{\mathrm{D}}$. For the $800{ }^{\circ} \mathrm{C}$-treated hematite film, the incorporation of both $\mathrm{Sn}^{4+}$ and $\mathrm{Zn}^{2+}$ dopants increased the $\mathrm{N}_{\mathrm{D}}$.

On the other hand, the estimated $\mathrm{V}_{\mathrm{FB}}$ values were $\sim 0.20 \mathrm{~V}_{\mathrm{RHE}}$ for $500{ }^{\circ} \mathrm{C}$-treated hematite films and $\sim 0.3 \mathrm{~V}_{\mathrm{RHE}}$ for $800^{\circ} \mathrm{C}$-treated hematite films. It is worth to mention that our results were different from those reported in literature. For instance, a typical value of $V_{F B}$ is about 

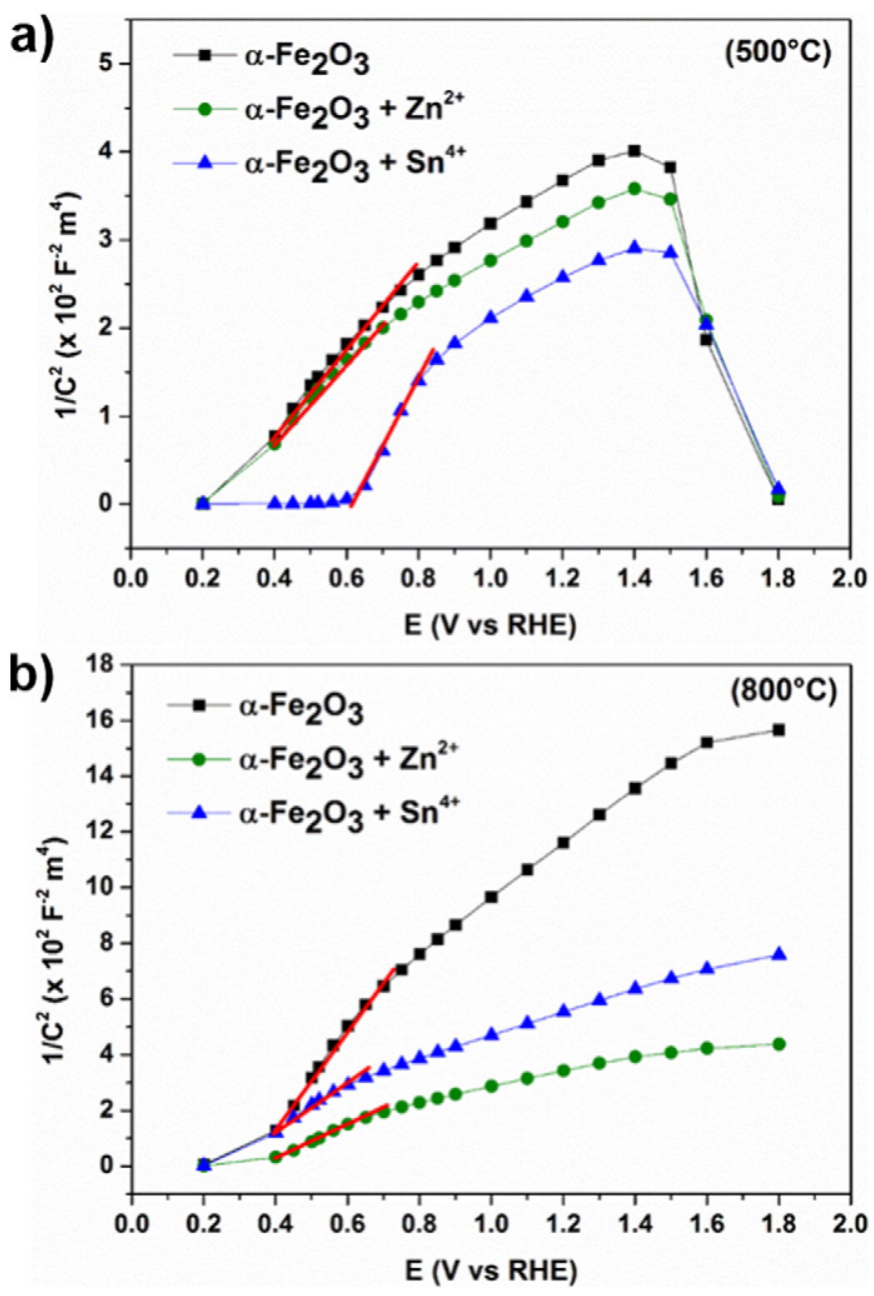

Fig. 6. Mott-Schottky plots recorded at $1 \mathrm{kHz}$ of hematite films prepared at: (a) $500{ }^{\circ} \mathrm{C}$ and (b) $800{ }^{\circ} \mathrm{C}$.

$0.5 \mathrm{~V}_{\mathrm{RHE}}[40,46]$ in which the photocurrent onset potential is around $0.8 \mathrm{~V}_{\mathrm{RHE}}$. In addition, regarding films prepared at the same temperature, it seemed that the incorporation of $\mathrm{Zn}^{2+}$ did not practically influenced on the $\mathrm{V}_{\mathrm{FB}}$, whereas, the incorporation of $\mathrm{Sn}^{4+}$ affected drastically the $\mathrm{V}_{\mathrm{FB}}$ in comparison with the $\mathrm{V}_{\mathrm{FB}}$ of the undoped film.

The pseudo-overpotentials of water oxidation $\left(\eta_{\text {ox }}\right)$ were also calculated from the estimated flat band potentials (Table 3 ). Large overpotentials were found for most of the films, but, interestingly, the Sn-modified hematite film prepared at $500{ }^{\circ} \mathrm{C}$ had the lowest overpotential. In general, these results confirmed that the influence of $\mathrm{Sn}^{4+}$ on the onset potential for the OER is quite different with that of the $\mathrm{Zn}^{2+}$.

One important parameter that also may affect the photocatalytic properties of hematite films is the depletion layer width $(W)$. The $W$ values for all the hematite films were calculated by using the following equation:

$W=\sqrt{\frac{2 \varepsilon \varepsilon_{0}}{e N_{D}}\left(V-V_{F B}-\frac{k T}{q}\right)}$

where all the variables and constants have the same meanings as those of constants in Eq. (4). In Table 3 is the depletion layer widths of hematite films calculated at $1.23 \mathrm{~V}_{\text {RHE}}$. Results showed that slightly higher $W$ values were found for $800{ }^{\circ} \mathrm{C}$-treated films in comparison with those of $500{ }^{\circ} \mathrm{C}$-treated films. It is well known that the separation of the photogenerated charges is enhanced in depletion layers having smaller widths because of the high electric field intensity. Therefore, electric field intensity experienced by the hole-electron pairs was slightly greater into the $500{ }^{\circ} \mathrm{C}$-treated hematite film than that into the $800{ }^{\circ} \mathrm{C}$-treated hematite films. Nevertheless, since the performances of $500{ }^{\circ} \mathrm{C}$-treated hematite film were not good as those of the $800{ }^{\circ} \mathrm{C}$-treated hematite film, the depletion layer width did not play an important role for the increasing the photocurrent.

In order to understand better the effect of doping and especially of thermal treatment temperature on the performances of hematite films, the contact angles of a water drop over the surface of hematite films were measured. As shown in Fig. 7, the degree in which the water drop spread over the film surface was influenced by the annealing temperature and doping. The $800{ }^{\circ} \mathrm{C}$-treated hematite film had lower contact angles than those of the films prepared at $500{ }^{\circ} \mathrm{C}$, meaning that $800{ }^{\circ} \mathrm{C}$-treated hematite films had a higher wettability.

In relation to films prepared at the same temperature, the addition of $\mathrm{Sn}^{4+}$ and $\mathrm{Zn}^{2+}$ into hematite films improved the wettability (reduced the contact angles) when compared with the wettability of the undoped hematite films. In addition, this description was in good agreement with the average contact angles calculated from Fig. 7 (see Table 4).

It is known that various parameters, such as surface energy, surface cleanliness and surface roughness, can affect the contact angles [47]. Because SEM images suggested that films prepared at higher temperatures had higher roughness, it seemed that contact angles of the films were mainly influenced by the surface roughness. In order to prove this hypothesis, AFM images of the films were obtained (Fig. 8). Our results showed confirmed that the surface of $500{ }^{\circ} \mathrm{C}$-treated hematite films was smooth whereas the surface of the $800{ }^{\circ} \mathrm{C}$-treated hematite film surface was significantly rough. Moreover, in order to evaluate the roughness of the film surface quantitatively, the $\boldsymbol{R}_{\boldsymbol{q}}$ value (RMS roughness) was calculated. The $\boldsymbol{R}_{\boldsymbol{q}}$ value is defined as the standard deviation of height values [48]:

$\boldsymbol{R}_{\boldsymbol{q}}=\sqrt{\frac{\sum\left(\boldsymbol{Z}_{\boldsymbol{i}}-\boldsymbol{Z}_{\boldsymbol{m}}\right)^{2}}{\boldsymbol{N}}}$

where $\boldsymbol{Z}_{\boldsymbol{i}}$ is a specific height value (obtained from AFM data), $\boldsymbol{Z}_{\boldsymbol{m}}$ is the average of the all height values and $\boldsymbol{N}$ is the number of height values recorded. The calculated $\boldsymbol{R}_{\boldsymbol{q}}$ values are displayed in Table 4. Results were consistent with the roughness analysis based only on AFM micrographs (Fig. 8 ) because the roughest films $\left(800{ }^{\circ} \mathrm{C}\right.$ ) had the highest $\boldsymbol{R}_{\boldsymbol{q}}$ values while the smoothest films $\left(500{ }^{\circ} \mathrm{C}\right.$ ) had the lowest $\boldsymbol{R}_{\boldsymbol{q}}$ values. Therefore, these surface studies demonstrated that the affinity

Table 3

Electronic parameters estimated from Mott-Schottky curves.

\begin{tabular}{|c|c|c|c|c|}
\hline Film & $\mathrm{N}_{\mathrm{D}}\left(\times 10^{19} \mathrm{~cm}^{-3}\right)$ & $\mathrm{V}_{\mathrm{FB}}\left(\mathrm{V}\right.$ vs $\left.\mathrm{V}_{\mathrm{RHE}}\right)$ & $\eta_{\mathrm{ox}}$ & $\mathrm{W}(\mathrm{nm})$ at $1.23 \mathrm{~V}_{\mathrm{RHE}}$ \\
\hline$\alpha-\mathrm{Fe}_{2} \mathrm{O}_{3}\left(500{ }^{\circ} \mathrm{C}\right)$ & 3.79 & 0.19 & 0.43 & 15.4 \\
\hline$\alpha-\mathrm{Fe}_{2} \mathrm{O}_{3}+\mathrm{Sn}^{4+}\left(500{ }^{\circ} \mathrm{C}\right)$ & 2.19 & 0.60 & 0.05 & 15.6 \\
\hline$\alpha-\mathrm{Fe}_{2} \mathrm{O}_{3}+\mathrm{Zn}^{2+}\left(500^{\circ} \mathrm{C}\right)$ & 4.05 & 0.20 & 0.40 & 14.8 \\
\hline$\alpha-\mathrm{Fe}_{2} \mathrm{O}_{3}\left(800{ }^{\circ} \mathrm{C}\right)$ & 1.00 & 0.30 & 0.28 & 28.3 \\
\hline$\alpha-\mathrm{Fe}_{2} \mathrm{O}_{3}+\mathrm{Sn}^{4+}\left(800^{\circ} \mathrm{C}\right)$ & 2.04 & 0.23 & 0.41 & 20.6 \\
\hline$\alpha-\mathrm{Fe}_{2} \mathrm{O}_{3}+\mathrm{Zn}^{2+}\left(800^{\circ} \mathrm{C}\right)$ & 2.98 & 0.33 & 0.25 & 16.1 \\
\hline
\end{tabular}




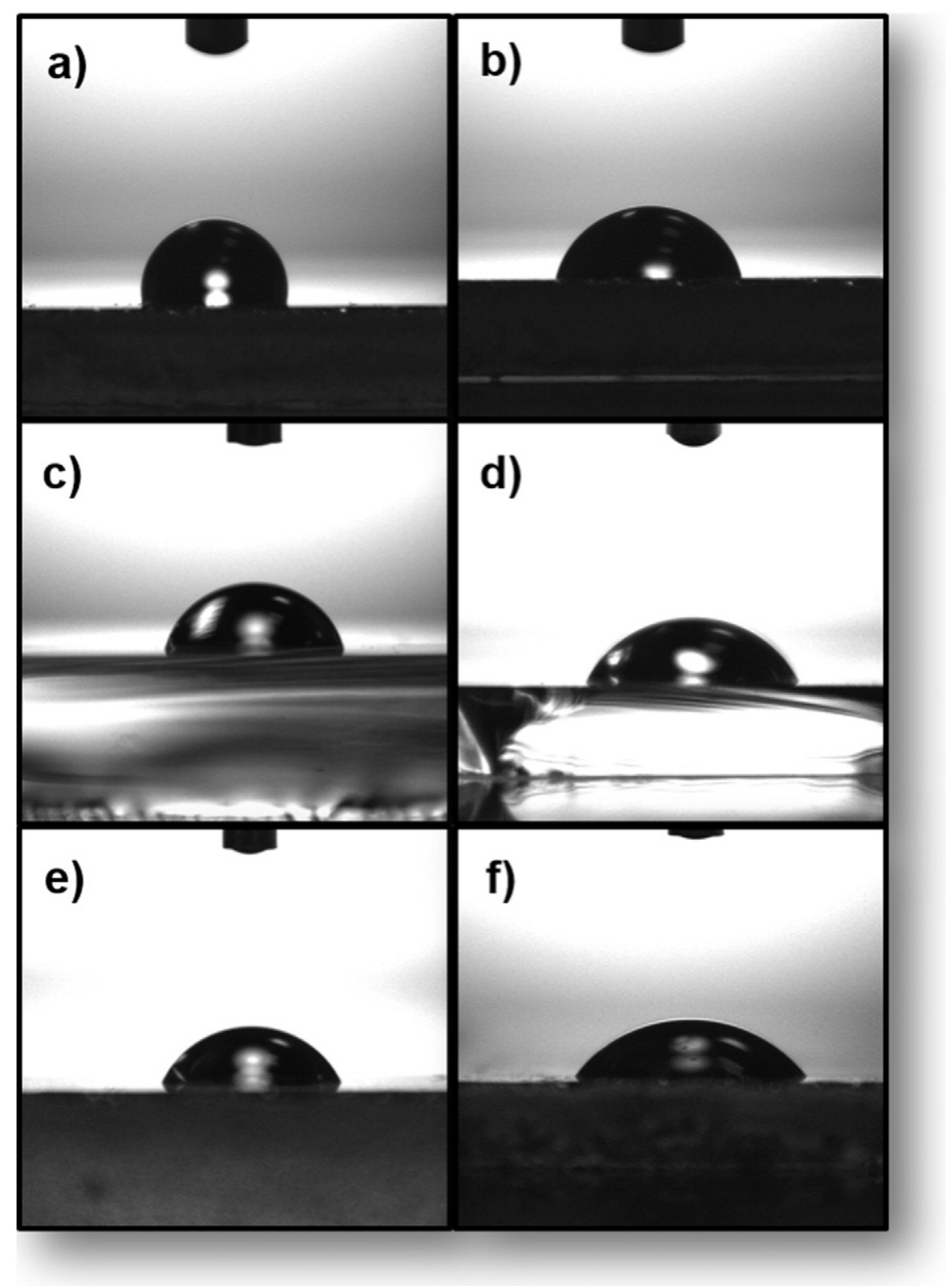

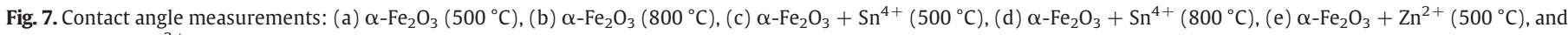
(f) $\alpha-\mathrm{Fe}_{2} \mathrm{O} 3+\mathrm{Zn}^{2+}\left(800{ }^{\circ} \mathrm{C}\right)$.

of hematite films with water is influenced by the surface roughness. The $800{ }^{\circ} \mathrm{C}$-treated hematite films had a higher wettability because they had higher $\boldsymbol{R}_{\boldsymbol{q}}$ values than those of $500{ }^{\circ} \mathrm{C}$-treated hematite films.

\section{Discussion}

As shown in Fig. 5, the thermal treatment temperature influenced on the photocatalytic properties of hematite films: the $800{ }^{\circ} \mathrm{C}$-treated hematite films held higher photocurrent densities and were more stable in comparison with those of the $500{ }^{\circ} \mathrm{C}$-treated hematite films. This difference in the photocatalytic properties of the films is caused by

Table 4

Average contact angles and Roughness values for hematite films.

\begin{tabular}{lcr}
\hline Film & Average contact angle & $\mathrm{R}_{\mathrm{q}}(\mathrm{nm})$ \\
\hline$\alpha-\mathrm{Fe}_{2} \mathrm{O}_{3}\left(500{ }^{\circ} \mathrm{C}\right)$ & 160.26 & 6.47 \\
$\alpha-\mathrm{Fe}_{2} \mathrm{O}_{3}+\mathrm{Sn}^{4+}\left(500{ }^{\circ} \mathrm{C}\right)$ & 80.56 & 4.87 \\
$\alpha-\mathrm{Fe}_{2} \mathrm{O}_{3}+\mathrm{Zn}^{2+}\left(500^{\circ} \mathrm{C}\right)$ & 67.95 & 5.76 \\
$\alpha-\mathrm{Fe}_{2} \mathrm{O}_{3}\left(800{ }^{\circ} \mathrm{C}\right)$ & 78.80 & 15.35 \\
$\alpha-\mathrm{Fe}_{2} \mathrm{O}_{3}+\mathrm{Sn}^{4+}\left(800^{\circ} \mathrm{C}\right)$ & 66.86 & 8.66 \\
$\alpha-\mathrm{Fe}_{2} \mathrm{O}_{3}+\mathrm{Zn}^{2+}\left(800^{\circ} \mathrm{C}\right)$ & 53.92 & 11.64 \\
\hline
\end{tabular}

degree of the wettability. The $800{ }^{\circ} \mathrm{C}$-treated hematite film exhibited a high wettability (lower contact angles) whereas $500{ }^{\circ} \mathrm{C}$-treated hematite film had a poor affinity with water (higher contact angles). In addition, the wettability of the films was strongly influenced by surface roughness, that is, films with high wettability had higher RMS roughness. Evidently, the difference in the roughness of hematite films was caused by thermal treatment temperature. Therefore, temperature strongly influenced on the catalytic response of hematite films under illumination.

The photoresponse of hematite films was affected not only by thermal treatment temperature but also by doping. In relation with $500{ }^{\circ} \mathrm{C}$-treated hematite film a different photocatalytic performance depending on which dopant, $\mathrm{Sn}^{4+}$ or $\mathrm{Zn}^{2+}$, was inserted. The $500{ }^{\circ} \mathrm{C}$ treated hematite film modified with $\mathrm{Zn}^{2+}$ had a poor performance as that of the undoped film, while the film modified with $\mathrm{Sn}^{4+}$ slightly improved the photocurrent density. As demonstrated in EIS results, both $\mathrm{Zn}^{2+}$ and $\mathrm{Sn}^{4+}$ were incorporated into hematite structure since the $N_{D}$ values of the modified films were different to that of undoped film. Moreover, the modified films had a better wettability in comparison with that of the undoped film. Therefore, it was expected that both dopants would increase the photocurrent of hematite film. Since 
a)
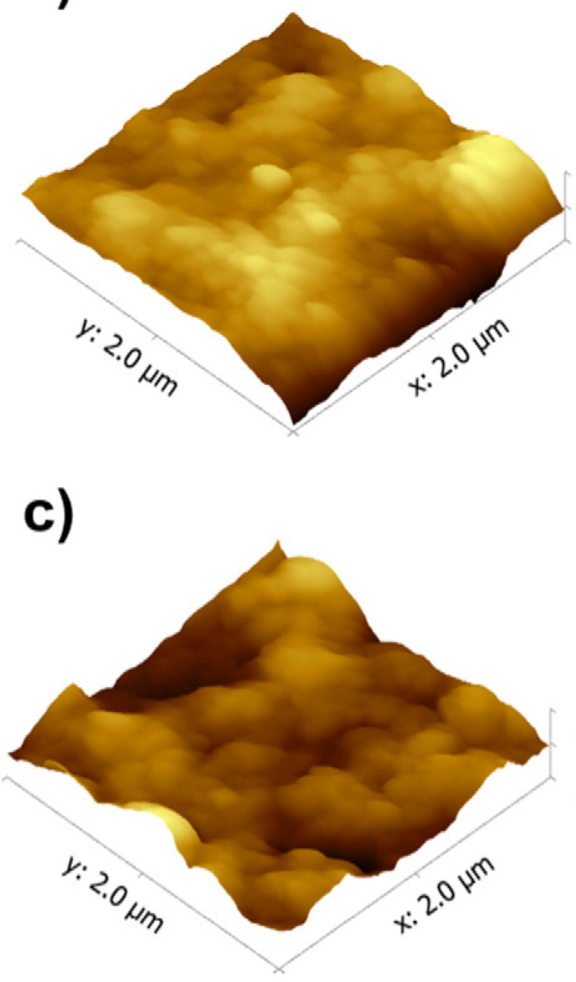

e)

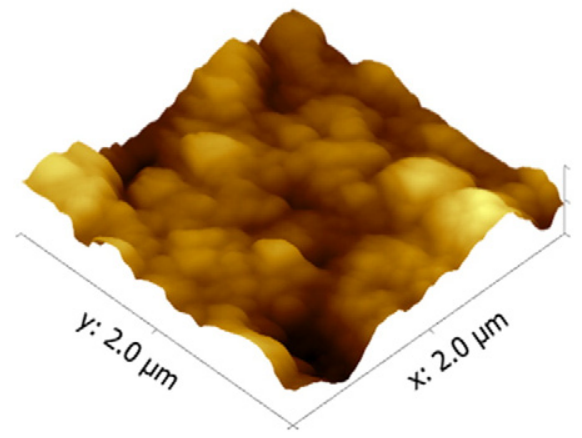

b)

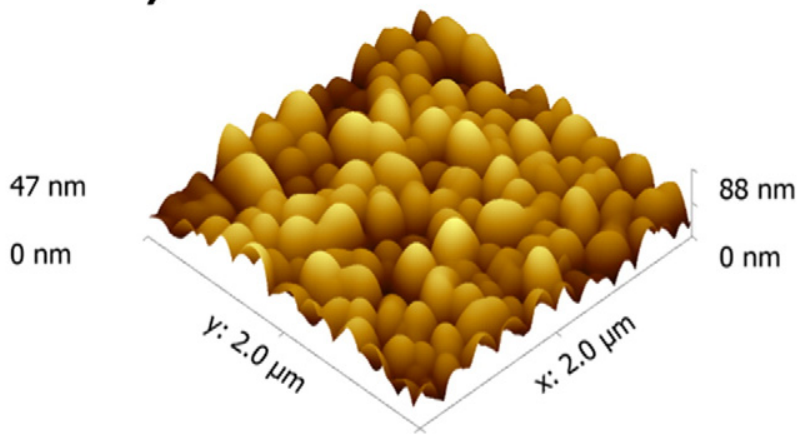

d)

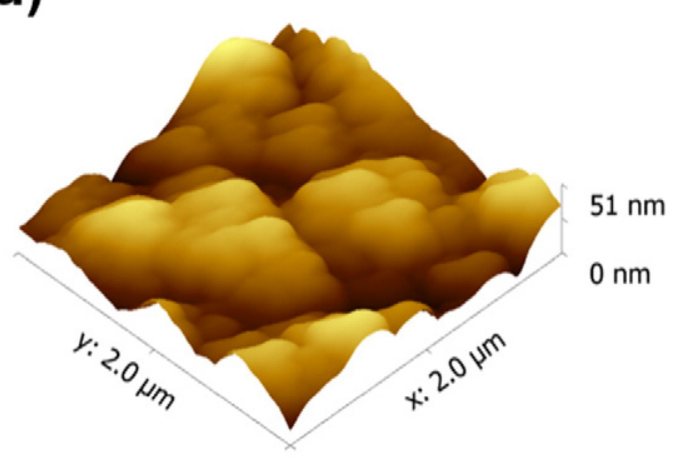

f)

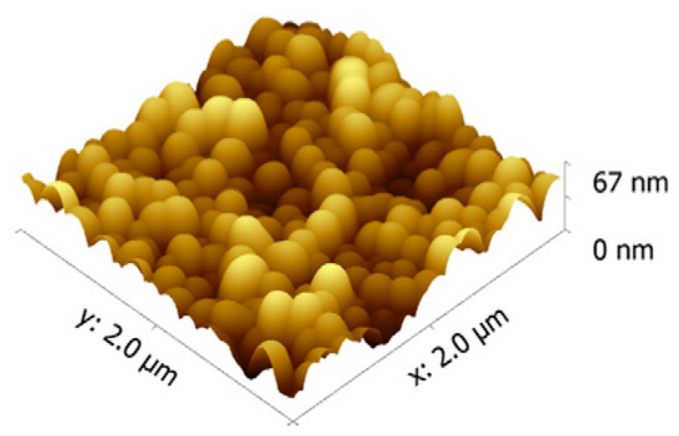

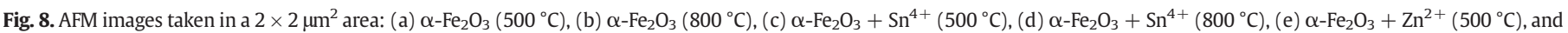
(f) $\alpha-\mathrm{Fe}_{2} \mathrm{O}_{3}+\mathrm{Zn}^{2+}\left(800{ }^{\circ} \mathrm{C}\right)$.

only the modification of the hematite film with $\mathrm{Sn}^{4+}$ caused an improvement, we believe that $\mathrm{Zn}^{2+}$ impurities were acting as recombination sites, resulting in a poor efficiency of surface chemical reactions.

As mentioned above, the incorporation of $\mathrm{Sn}^{+4}$ into the $500^{\circ}$-treated hematite film slightly enhanced the photoelectrochemical performance whereas the incorporation of $\mathrm{Zn}^{+2}$ did not. Thus, it seems that most of dopants were not efficiently incorporated and, therefore, they may have segregated. By using the SCDS method, Souza et al. [17] reported that a certain concentration of dopants segregated at the grain boundaries of silicon-modified hematite films. Most importantly, the authors concluded that the segregation of silicon did not improve the catalytic response of the films; rather, it promoted the recombination rate of hole-electron pairs. That is why the performance of the $\mathrm{Si}(2.0 \%)-$ modified hematite film was as poor as that of the undoped film, whereas the $\mathrm{Si}(0.5 \%)$-modified hematite film had the best performance. However, segregation of dopants does not always worsen the photocatalytic performance of hematite films because the segregation caused the formation of unintentional composites that can exhibit a better photocatalytic performance than that of the single electrode. Shen et al. [49] demonstrated that the performance for water splitting of hematite nanorod electrodes modified with a thin layer of $\mathrm{WO}_{3}$ (composite) was better than that of undoped film. Nevertheless, we believe that a certain concentration of dopants segregated and acted as recombination sites because it was not observed a great improvement on the catalytic response of $\mathrm{Sn}$ and Zn-modified hematite films; otherwise, segregation would have improved the performance for the OER under illumination.

Unlike the modified $500{ }^{\circ} \mathrm{C}$-treated hematite film, both $\mathrm{Sn}^{4+}$ and $\mathrm{Zn}^{2+}$ dopants increased the generated photocurrent of $800{ }^{\circ} \mathrm{C}$-treated hematite films. This improvement was attributed to doping since the incorporation of the dopants increased the $\mathrm{N}_{\mathrm{D}}$ value in comparison with the $N_{D}$ of the undoped film. Moreover, we believed that the increase in the $\mathrm{N}_{\mathrm{D}}$ was also caused by the unintentional doping of $\mathrm{Sn}^{4+}$ ions from the $\mathrm{F}-\mathrm{SnO}_{2}$ layer. Many authors have reported that the diffusion of the tin ions from the FTO layer is promoted at high temperatures as $800{ }^{\circ} \mathrm{C}[43,50]$, enhancing the photoelectrochemical performance of the hematite electrodes. As shown in the ESI results, doping with $\mathrm{Sn}^{4+}$ doubled the $\mathrm{N}_{\mathrm{D}}$ value, while the $\mathrm{Zn}$-modified film had almost 


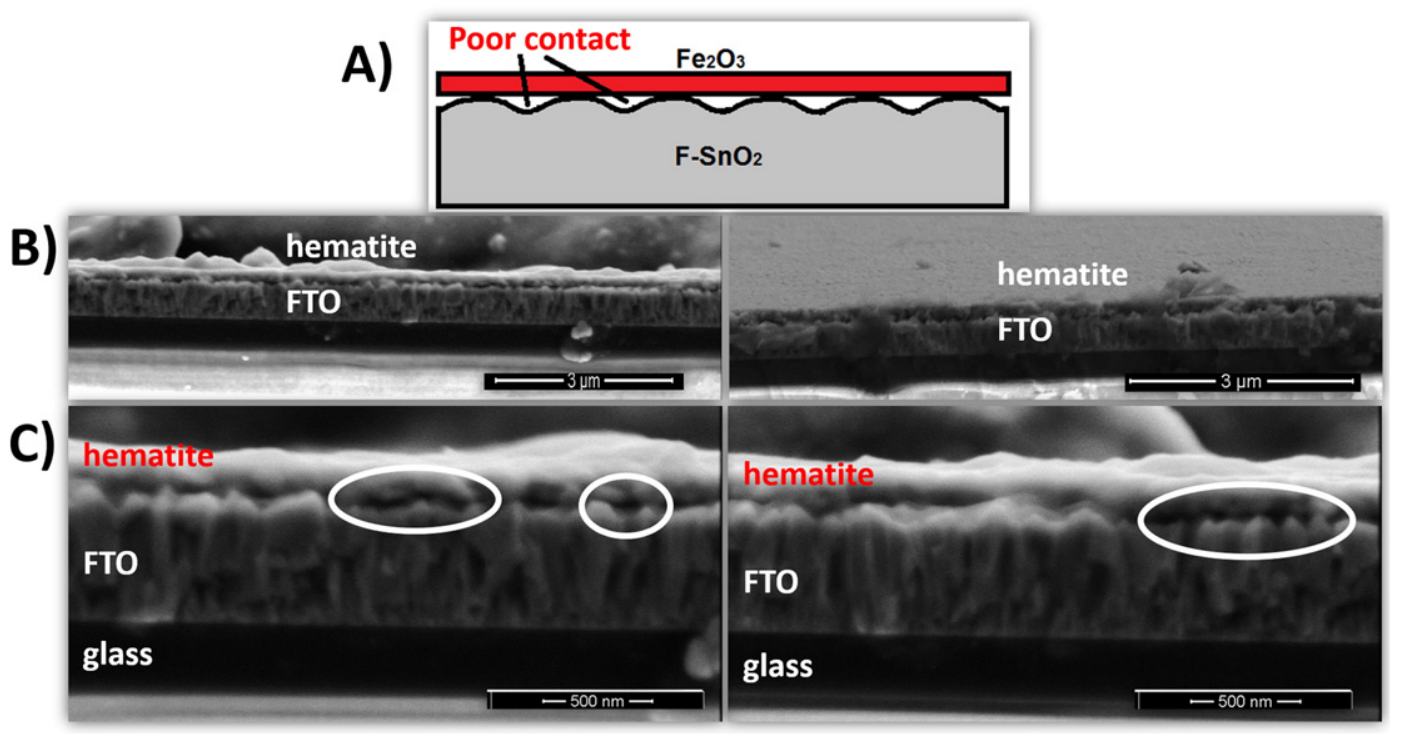

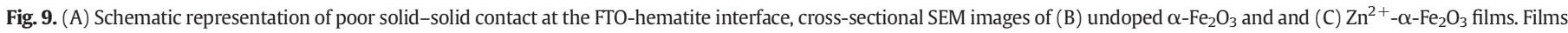
thermal treated at $800{ }^{\circ} \mathrm{C}$ in air.

threefold the $N_{D}$ value of the undoped film. A similar increase in the $N_{D}$ was not found for $500{ }^{\circ} \mathrm{C}$-treated hematite film.

In spite of the higher photocurrent densities of the modified $800{ }^{\circ} \mathrm{C}$-treated hematite film, it is probable that dopants segregated because they did not significantly improve the performance of hematite films. This fact is evident in Fig. 6, which showed that the relative increase in the photocurrent caused by the dopants (for $800{ }^{\circ} \mathrm{C}$-treated hematite film) was very similar to that observed in the Sn-modified $500{ }^{\circ} \mathrm{C}$-treated hematite film. In addition, the dopant segregation was also suggested by the SEM results since hematite grains of the modified films did not grow as much as those of the undoped film were. Dopant segregation may also be supported by the Raman results that demonstrated that the dopants reduced the intensity of Raman bands. That is, being segregated at the grain boundaries, dopants decreased the intensity of the laser by scattering, and, therefore, a less intense laser interacted with the hematite matrix, resulting in low intense Raman bands of the hematite matrix. However, further investigation must be conducted for a better understanding of the Raman results. Moreover, the possible segregation of dopants was also suggested by the contact angle results. As shown in Fig. 7, the addition of dopants reduced the contact angles, and this increase in the wettability is not caused by roughness since films had similar roughness. Rather, this effect may be caused by the segregation of dopants that improved the interaction of water with the film surface.

Despite the possible segregation of dopants, the performance of hematite films prepared by the SCDS method was poor. A reasonable explanation for this problem is the poor contact between hematite and $\mathrm{F}-\mathrm{SnO}_{2}$ layer as demonstrated in a previous report and illustrated in the Scheme of Fig. 9a [16]. The authors prepared undoped and Si-doped hematite films by using the polymerized complex method, and the photoelectrochemical results showed that hematite films generated low photocurrent densities. According to the STEM crosssectional images reported by Souza et al. [16], the hematite film displays only few points of contact between FTO and hematite layer. In order to confirm this hypothesis, in the present work, of poor hematite adherence onto the FTO substrate the cross-sectional analysis were conducted by using scanning electron microscopy (SEM). Indeed the crosssectional SEM images illustrated in Fig. 9b and $\mathrm{c}$ with different magnification revealed only few points of contact between FTO and undoped and $\mathrm{Zn}$-modified hematite layer. As consequence of this result a significant impact in the electronic properties can be expected such as; poor transference of charge from hematite to the FTO layer for all synthesized films. Moreover, this inhomogeneous hematite adherence can directly affect the photoelectrochemical performance by increasing the charge recombination rate due it low electron injection to the backcontact (FTO layer).

In summary, the hematite films prepared in this work need to be improved in order to obtain homogenous adherence between hematite and FTO layer, which may enhance the performance of hematite electrodes and make the SCDS method promise for commercial application.

\section{Conclusions}

Undoped and modified with $\mathrm{Sn}^{4+}$ and $\mathrm{Zn}^{2+}$ hematite films were synthesized by the SCDS method at two temperatures $\left(500{ }^{\circ} \mathrm{C}\right.$ and $800{ }^{\circ} \mathrm{C}$ ). It was demonstrated that the thermal treatment influenced on the photocatalytic performance of films. The $800{ }^{\circ} \mathrm{C}$-treated hematite film exhibited a better photocatalytic performance than that of $500{ }^{\circ} \mathrm{C}$-treated hematite film. The better performance of $800{ }^{\circ} \mathrm{C}$-treated films was attributed to their higher roughness that improved their wettability. In addition, based on the EIS results, a smaller amount of $\mathrm{Sn}^{4+}$ and $\mathrm{Zn}^{2+}$ can be incorporated into the hematite structure, and it resulted in a slightly improvement in the photoelectrochemical properties of the films (with exception of the Zn-modified $500{ }^{\circ} \mathrm{C}$-treated hematite film). Nevertheless, it seemed that most of the dopants segregated at the surface of the grain boundaries (confirmed by XRD data, which reduced the crystallite size) since a great improvement was not achieved by doping. Regardless of the dopant segregation, both undoped and modified hematite films exhibited a low performance for the water oxidation under illumination conditions. Indeed, the most plausible explanation is that the thermal treatment favored a poor contact point (illustrated in Fig. 9) of hematite film with FTO substrate due stress induced between of them, which prevented some of the photogenerated electrons from being harvested. In order to improve the hematite adherence onto the FTO layer and make the SCDS a promise method for commercial applications further experiments are underway in our laboratory.

\section{Acknowledgments}

We acknowledge the financial support from the Brazilian agencies FAPESP (Sao Paulo Research Foundation) (proc. nr. 2012/19926-8 and 2011/19924-2), CNPq (The National Council for Scientific and Technological Development) (473669/2012-9), CEPID/CDMF (Center for the 
development Functional Materials) FAPESP (2013/07296-2), CAPES (Coordenação de Aperfeiçoamento de Pessoal de Nível Superior), CEM-UFABC (Multiuser Experimental Center of Federal University of $A B C)$. We also thank Prof. Edson R. Leite for the SEM images obtained at the Nanocharacterization Laboratory, UFSCar.

\section{References}

[1] I.E. AGENCY, Key World Energy Statistics, 2013.

[2] BP Company, BP Statistical Review of World Energy June 2014, 2014.

[3] K.H. Solangi, M.R. Islam, R. Saidur, N.A. Rahim, H. Fayaz, A review on global solar energy policy, Renew. Sust. Energ. Rev. 15 (2011) 2149-2163.

[4] R. van de Krol, M. Gratzel, Photoelectrochemical Hydrogen Production, Springer Science, 2012

[5] Z. Wang, R.R. Roberts, G.F. Naterer, K.S. Gabriel, Comparison of thermochemical, electrolytic, photoelectrolytic and photochemical solar-to-hydrogen production technologies, Int. J. Hydrog. Energy 37 (2012) 16287-16301.

[6] I. Dincer, Green methods for hydrogen production, Int. J. Hydrog. Energy 37 (2012) 1954-1971.

[7] P. Liao, M.C. Toroker, E.A. Carter, Electron transport in pure and doped hematite, Nano Lett. 11 (2011) 1775-1781.

[8] K. Sivula, F. Le Formal, M. Grätzel, Cover picture: solar water splitting: progress using hematite $\left(\alpha-\mathrm{Fe}_{2} \mathrm{O}_{3}\right)$ photoelectrodes (ChemSusChem 4/2011), ChemSusChem 4 (2011) 417.

[9] M.H. Lee, J.H. Park, H.S. Han, H.J. Song, I.S. Cho, J.H. Noh, K.S. Hong, Nanostructured Ti-doped hematite $\left(\alpha-\mathrm{Fe}_{2} \mathrm{O}_{3}\right)$ photoanodes for efficient photoelectrochemical water oxidation, Int. J. Hydrog. Energy 39 (2014) 17501-17507.

[10] L. Wang, C.-Y. Lee, A. Mazare, K. Lee, J. Müller, E. Spiecker, P. Schmuki, Enhancing the water splitting efficiency of Sn-doped hematite nanoflakes by flame annealing, Chem. Eur. J. 20 (2014) 77-82.

[11] C.-Y. Lee, L. Wang, Y. Kado, R. Kirchgeorg, P. Schmuki, Si-doped Fe2O3 nanotubular/ nanoporous layers for enhanced photoelectrochemical water splitting, Electrochem. Commun. 34 (2013) 308-311.

[12] J. Frydrych, L. Machala, J. Tucek, K. Siskova, J. Filip, J. Pechousek, K. Safarova, M. Vondracek, J.H. Seo, O. Schneeweiss, M. Gratzel, K. Sivula, R. Zboril, Facile fabrication of tin-doped hematite photoelectrodes - effect of doping on magnetic properties and performance for light-induced water splitting, J. Mater. Chem. 22 (2012) 23232-23239.

[13] S. Kumari, A.P. Singh, C. Tripathi, D. Chauhan, S. Dass, R. Shrivastav, V. Gupta, K. Sreenivas, V.R. Satsangi, Enhanced photoelectrochemical response of Zn-dotted hematite, Int. J. Photoenergy 2007 (2007) 6.

[14] Y. Liu, Y.-X. Yu, W.-D. Zhang, Photoelectrochemical properties of Ni-doped $\mathrm{Fe}_{2} \mathrm{O}_{3}$ thin films prepared by electrodeposition, Electrochim. Acta 59 (2012) 121-127.

[15] F.L. Souza, K.P. Lopes, E. Longo, E.R. Leite, The influence of the film thickness of nanostructured [small alpha]- $\mathrm{Fe}_{2} \mathrm{O}_{3}$ on water photooxidation, Phys. Chem. Chem. Phys. 11 (2009) 1215-1219.

[16] F.L. de Souza, A.M. Xavier, W.M. de Carvalho, R.H. Gonçalves, E.R. Leite, Facile routes to produce hematite film for hydrogen generation from photoelectro-chemical water splitting, in: F.L. de Souza, E.R. Leite (Eds.), Nanoenergy: Nanotechnology Applied for Energy Production, Springer-Verlag, Berlin Heidelberg, 2013.

17] F.L. Souza, K.P. Lopes, P.A.P. Nascente, E.R. Leite, Nanostructured hematite thin films produced by spin-coating deposition solution: application in water splitting, Sol Energy Mater. Sol. Cells 93 (2009) 362-368.

[18] A.M. Xavier, F.F. Ferreira, F.L. Souza, Morphological and structural evolution from akaganeite to hematite of nanorods monitored by ex situ synchrotron X-ray powder diffraction, RSC Adv. 4 (2014) 17753-17759.

[19] H. MIURA, CellCalc, Department of Earth and Planetary Sciences, Graduate School of Science, Hokkaido University, Sapporo, Japan, Pp. CellCalc is a Windows Program to Calculated Unit Cell Parameters and Their Standard Deviations From Observed D-Value and HKL Data, 2003.

[20] R. Shannon, Revised effective ionic radii and systematic studies of interatomic distances in halides and chalcogenides, Acta Crystallogr. A 32 (1976) 751-767.

[21] J.Z. Jiang, R. Lin, K. Nielsen, S. Mørup, D.G. Rickerby, R. Clasen, Interstitial positions of tin ions in $\alpha-\left(\mathrm{Fe}_{\mathrm{rich}} \mathrm{Sn}\right)_{2} \mathrm{O}_{3}$ solid solutions prepared by mechanical alloying, Phys. Rev. B 55 (1997) 14830-14835.

[22] M. Sorescu, L. Diamandescu, D. Tarabasanu-Mihaila, V.S. Teodorescu, B.H. Howard, Hydrothermal synthesis and structural characterization of $(1-\mathrm{x}) \alpha-$ $\mathrm{Fe}_{2} \mathrm{O}_{3}-{ }_{\mathrm{x}} \mathrm{SnO}_{2}$ nanoparticles, J. Phys. Chem. Solids 65 (2004) 1021-1029.

[23] H. Uchiyama, M. Yukizawa, H. Kozuka, Photoelectrochemical properties of $\mathrm{Fe}_{2} \mathrm{O}_{3}-\mathrm{SnO}_{2}$ films prepared by sol-gel method, J. Phys. Chem. C 115 (2011) 7050-7055.
[24] T. Ami, M. Suzuki, MOCVD growth of (100)-oriented $\mathrm{CeO}_{2}$ thin films on hydrogenterminated Si(100) substrates, Mater. Sci. Eng., B 54 (1998) 84-91.

[25] A. Kay, I. Cesar, M. Grätzel, New benchmark for Water photooxidation by nanostructured $\alpha-\mathrm{Fe}_{2} \mathrm{O}_{3}$ films, J. Am. Chem. Soc. 128 (2006) 15714-15721.

[26] A. Monshi, M. Foroughi, M. Monshi, Modified Sherrer equation to estimate more accurately nano-crystallie size using XRD, World J. Nano Sci. Eng. 2 (2012).

[27] J.I. Langford, A.J.C. Wilson, Scherrer after sixty years: a survey and some new results in the determination of crystallite size, J. Appl. Crystallogr. 11 (1978) 102-113.

[28] F.L. Souza, K.P. Lopes, E. Longo, E.R. Leite, The influence of the film thickness of nanostructured a- $\mathrm{Fe}_{2} \mathrm{O}_{3}$ on water photooxidation, Phys. Chem. Chem. Phys. 11 (2009) 1215-1219.

[29] A.M. Jubb, H.C. Allen, Vibrational spectroscopic characterization of hematite, maghemite, and magnetite thin films produced by vapor deposition, ACS Appl. Mater. Interfaces 2 (2010) 2804-2812.

[30] I.V. Chernyshova, M.F. Hochella Jr., A.S. Madden, Size-dependent structural transformations of hematite nanoparticles. 1. phase transition, Phys. Chem. Chem. Phys. 9 (2007) 1736-1750.

[31] V.C. Farmer, Differing effects of particle size and shape in the infrared and Raman spectra of kaolinite, Clay Miner. 33 (1998) 601-604.

[32] I. Cesar, K. Sivula, A. Kay, R. Zboril, M. Grätzel, Influence of feature size, film thickness, and silicon doping on the performance of nanostructured hematite photoanodes for solar water splitting, J. Phys. Chem. C 113 (2009) 772-782.

[33] A. Yogi, D. Varshney, Magnetic and structural properties of pure and $\mathrm{Cr}$-doped haematite: $\alpha-\mathrm{Fe}_{2}-{ }_{\mathrm{x}} \mathrm{Cr}_{\mathrm{x}} \mathrm{O}_{3}(0 \leq \mathrm{x} \leq 1)$, J. Adv. Ceram. 2 (2013) 360-369.

[34] Y.-S. Hu, A. Kleiman-Shwarsctein, A.J. Forman, D. Hazen, J.-N. Park, E.W. McFarland, Pt-doped $\alpha-\mathrm{Fe}_{2} \mathrm{O}_{3}$ thin films active for photoelectrochemical water splitting, Chem. Mater. 20 (2008) 3803-3805.

[35] T.W. Hamann, Splitting water with rust: hematite photoelectrochemistry, Dalton Trans. 41 (2012) 7830-7834.

[36] X. Lian, X. Yang, S. Liu, Y. Xu, C. Jiang, J. Chen, R. Wang, Enhanced photoelectrochemical performance of Ti-doped hematite thin films prepared by the sol-gel method, Appl. Surf. Sci. 258 (2012) 2307-2311.

[37] O. Zandi, T.W. Hamann, Enhanced water splitting efficiency through selective surface state removal, J. Phys. Chem. Lett. 5 (2014) 1522-1526.

[38] Y. Ling, G. Wang, D.A. Wheeler, J.Z. Zhang, Y. Li, Sn-doped hematite nanostructures for photoelectrochemical Water splitting, Nano Lett. 11 (2011) 2119-2125.

[39] R. Jiang, C. Chen, S. Zheng, The non-linear fitting method to analyze the measured M-S plots of bipolar passive films, Electrochim. Acta 55 (2010) 2498-2504.

[40] F. Le Formal, N. Tetreault, M. Cornuz, T. Moehl, M. Gratzel, K. Sivula, Passivating surface states on water splitting hematite photoanodes with alumina overlayers, Chem. Sci. 2 (2011) 737-743.

[41] J. Leduc, S.M. Ahmed, Photoelectrochemical and impedance characteristics of specular hematite. 2. Deep bulk traps in specular hematite at small a.c. frequencies, J. Phys. Chem. 92 (1988) 6661-6665.

[42] G. Horowitz, Capacitance-voltage measurements and flat-band potential determination on $\mathrm{Zr}$-doped $\alpha-\mathrm{Fe}_{2} \mathrm{O}_{3}$ single-crystal electrodes, J. Electroanal. Chem. Interfacial Electrochem. 159 (1983) 421-436.

[43] N. Mirbagheri, D. Wang, C. Peng, J. Wang, Q. Huang, C. Fan, E.E. Ferapontova, Visible light driven photoelectrochemical water oxidation by $\mathrm{Zn}$ - and Ti-doped hematite nanostructures, ACS Catal. 4 (2014) 2006-2015.

[44] Z. Fu, T. Jiang, Z. Liu, D. Wang, L. Wang, T. Xie, Highly photoactive Ti-doped $\alpha-$ $\mathrm{Fe}_{2} \mathrm{O}_{3}$ nanorod arrays photoanode prepared by a hydrothermal method for photoelectrochemical water splitting, Electrochim. Acta 129 (2014) 358-363.

[45] D. Cao, W. Luo, M. Li, J. Feng, Z. Li, Z. Zou, A transparent Ti4 + doped hematite photoanode protectively grown by a facile hydrothermal method, CrystEngComm 15 (2013) 2386-2391.

[46] K. Sivula, Metal oxide photoelectrodes for solar fuel production, surface traps, and catalysis, J. Phys. Chem. Lett. 4 (2013) 1624-1633.

[47] B. Bhushan, Y. Chae Jung, M. Nosonovsky, Lotus effect: surfaces with roughnessinduced superhydrophobicity, self-cleaning, and low adhesion, in: B. Bhushan (Ed.), Springer Handbook of Nanotechnology, Springer-Verlag, Berling Heidelberg, 2010

[48] J.D. Miller, S. Veeramasuneni, J. Drelich, M.R. Yalamanchili, G. Yamauchi, Effect of roughness as determined by atomic force microscopy on the wetting properties of PTFE thin films, Polym. Eng. Sci. 36 (1996) 1849-1855.

[49] S. Shen, C. Kronawitter, J. Jiang, S. Mao, L. Guo, Surface tuning for promoted charge transfer in hematite nanorod arrays as water-splitting photoanodes, Nano Res. 5 (2012) 327-336.

[50] K. Sivula, R. Zboril, F. Le Formal, R. Robert, A. Weidenkaff, J. Tucek, J. Frydrych, M. Grätzel, Photoelectrochemical water splitting with mesoporous hematite prepared by a solution-based colloidal approach, J. Am. Chem. Soc. 132 (2010) 7436-7444. 